\title{
Uruguay 2009: De Tabaré Vázquez a José MujicA*
} Uruguay 2009: From Tabaré Vázquez to José Mujica

\author{
ADOLFO GARCÉ \\ Instituto de Ciencia Política, Facultad de Ciencias Sociales, Universidad de la República
}

\begin{abstract}
RESUMEN
La política uruguaya, durante el año 2009, estuvo centrada en la competencia electoral. En junio se llevaron a cabo las elecciones primarias en las que los partidos seleccionaron sus candidatos a la presidencia. En octubre el Frente Amplio logró retener la mayoría absoluta en el parlamento. En noviembre, en el balotaje, José Mujica, candidato del partido de gobierno (Frente Amplio) derrotó a Luis Alberto Lacalle (del Partido Nacional). A pesar de la centralidad de la lucha electoral, el parlamento aprobó algunas leyes importantes, entre las que se destaca la creación de un tercer nivel de gobierno (municipios). El Presidente Tabaré Vázquez tuvo un protagonismo importante a lo largo del año y terminó su mandato con niveles muy altos de popularidad. A pesar de su pasado guerrillero y de haber prometido "un giro a la izquierda" durante la campaña por la candidatura presidencial por el FA el gobierno de Mujica ofrece más continuidad que cambio respecto al de Vázquez, desde el punto de vista de la orientación de las políticas públicas.
\end{abstract}

Palabras clave: Uruguay, elecciones nacionales, Frente Amplio, democracia directa, descentralización, cuota de género.

\begin{abstract}
Uruguayan politics, during 2009, was focused in political competition. In June, parties selected their presidential candidates in open primaries. In October, Frente Amplio succeeded in sustaining the majority in congress. In November, at Run-off, José Mujica (candidate of Frente Amplio) defeated Luis Alberto Lacalle (Partido Nacional). Despite de centrality of electoral competition, congress passed some important laws, like the creation of a third level of government (municipios). President Tabaré Vázquez had a leading role during the year, and finished his mandate with a high level of popularity. Despite his personal history as guerrillero and have promised a "turn to the left" during the internal presidential campaign in the FA, Mujica's government offers more continuity than change vis-à-vis Vázquez policies.
\end{abstract}

Key words: Uruguay, national elections, Frente Amplio, direct democracy, decentralization, gender quotas.

* Muchos colegas me ayudaron, de modos diversos, a preparar este artículo. Antonio Cardarello, Daniel Buquet, Daniel Chasquetti, Gustavo De Armas, Rafael Piñeiro y Jaime Yaffé, del ICP-FCS; Andrea Vigorito y Gabriela Mordecki del Instituto de Economía de la FCEyA; Gabriel Oddone y Rafael Mantero de CPA; Ignacio Zuasnábar y Alexandra Lizbona de Equipos-Mori; Oscar Roba, Susana Lamschtein y Silvana Barbot del Banco de Datos del Área Sociodemográfica del Banco de Datos de FCS. A todos ellos mi agradecimiento. 
En octubre de 2004 la historia política uruguaya entró en una nueva etapa: el Frente Amplio (en adelante FA), coalición de izquierda fundada en 1971, ganó las elecciones presidenciales por primera vez y obtuvo mayoría parlamentaria. El $1^{\circ}$ de marzo de 2005 Tabaré Vázquez asumió la presidencia. Durante los primeros tres años de su mandato, el gobierno del FA impulsó un ambicioso paquete de innovaciones. ${ }^{1}$ Algunas de las reformas más importantes terminaron de aprobarse durante 2007 (Chasquetti, 2008). En 2008 se fue agotando el impulso reformista y se desató la competencia electoral dentro de los partidos (Buquet, 2009). Culminando esta oscilación desde policies a politics, la política uruguaya de 2009 giró en torno a la realización de las elecciones primarias (en junio) y parlamentarias y presidenciales (en octubre y noviembre). ${ }^{2} \mathrm{Al}$ cabo de este proceso electoral, el FA logró retener la mayoría parlamentaria (en la elección de octubre) y la presidencia (fue necesario realizar un balotaje en noviembre). Simultáneamente a la elección nacional de octubre fueron realizados dos plebiscitos de reforma constitucional. A pesar de la centralidad de los procesos electrorales, durante el último año del primer gobierno del FA llegaron a aprobarse tres leyes muy importantes: i) negociación colectiva, ii) financiamiento de partidos políticos, iii) descentralización y participación y iv) ley de cuotas de género. Empecemos por presentar estas normas para concentrarnos, después, en el proceso electoral.

\section{EL ÚLTIMO AÑO DEL GOBIERNO DE VÁZQUEZ}

Tabaré Vázquez terminó el año 2008 políticamente debilitado. En noviembre y diciembre recibió dos golpes muy duros. Paradójicamente, no vinieron desde los partidos de oposición sino desde sus propias tiendas políticas. El primero de ellos tuvo por escenario el parlamento. La bancada frenteamplista aprobó la Ley de Salud Sexual y Reproductiva. Cumpliendo con un compromiso asumido públicamente antes de acceder a la presidencia, Tabaré Vázquez vetó los artículos de la ley que despenalizaban el aborto. La tensión entre el Presidente y la mayoría de la bancada frenteamplista fue muy fuerte y derivó, imprevistamente, en la renuncia de Vázquez al Partido Socialista (PS). El segundo golpe al liderazgo presidencial se verificó en el Congreso del FA, cuando la mayoría de los congresistas, en lugar de acompañar la indicación de Vázquez (que impulsó abiertamente la candidatura de Danilo Astori desde febrero de 2008), optó por designar a José Mujica como candidato "oficial" a la presidencia por el FA.

Un año después la situación era completamente distinta. A fines de 2009 Vázquez logró alcanzar niveles de popularidad, y de aprobación de gestión absolutamente inéditos. Para explicar la recuperación de la imagen del Presidente hay que tomar en cuenta al

1 Creación del Ministerio de Desarrollo Social y puesta en marcha de un Programa de Transferencias monetarias Condicionadas (PANES), creación de la Agencia Nacional de Investigación e Innovación, lanzamiento del Plan Ceibal (One Laptop per Child), reforma tributaria, reforma del sector salud (creación del Sistema Nacional Integrado de Salud), convocatoria a un debate nacional para la reforma de la Ley de Educación, fuerte aumento del presupuesto para la enseñanza, etc. Para tener un panorama de los cambios realizados por el gobierno de Vázquez ver Elissalde (2009).

2 Una escueta y muy precisa descripción del proceso electoral 2009 y de su marco institucional puede leerse en Altman (2010). 
menos dos factores políticos. En primer lugar, la estrategia de comunicación desplegada. Desde marzo a noviembre, Vázquez llevó adelante una defensa muy contundente de su gestión de gobierno. Se valió de tres recursos: actos públicos de "rendición de cuentas", viajes al exterior e inauguraciones de obras. Durante toda su presidencia Vázquez insistió mucho en su compromiso de "rendir cuentas" de lo realizado frente a la ciudadanía. Los actos de "rendición de cuentas" (como el del 7 de marzo de 2009 en la Avenida 18 de Julio o como los Consejos de Ministros abiertos en Bella Unión, Villa Soriano y Zapicán ${ }^{3}$ ) le permitieron evitar que el protagonismo político se concentrara completamente en los movimientos de los diversos candidatos. Además constituyeron la mejor tribuna, por prestigio y resonancia, para ejercer la defensa de su gestión. Los viajes también favorecieron el mismo objetivo. En septiembre, en uno de los meses centrales de la campaña electoral, su viaje a EE.UU. le permitió captar la atención de los medios y de la opinión pública. Su reunión con Hillary Clinton y su presencia en la ONU reforzaron su imagen de estadista respetado por sus pares. ${ }^{4}$ Finalmente, como cualquier presidente que pretende cosechar políticamente lo sembrado durante años, dedicó una parte de su tiempo a participar en actividades de alto contenido simbólico. El mes de octubre fue especialmente prolífico desde este punto de vista. Clausuró el Plan Ceibal entregando las últimas computadoras portátiles a escolares $(13 / 10),{ }^{5}$ inauguró la nueva terminal del aeropuerto internacional de Carrasco (5/10) y la nueva terminal de contenedores del puerto de Montevideo (12/10). En el acto de apertura de la nueva terminal aérea, además, sorpresivamente, invitó al ex presidente Jorge Batlle (Partido Colorado) a cortar la cinta, en un gesto que fue muy bien recibido por los partidos de oposición.

Vázquez, como puede verse, hizo mucho por contribuir al fortalecimiento de su propia imagen. Sin embargo, no puede explicarse el excelente desempeño presidencial en materia de opinión pública durante su último año de gobierno sin tomar en cuenta las posiciones asumidas por otros actores. En este sentido hay que destacar que José Mujica, al igual que los otros dos precandidatos frenteamplistas, Danilo Astori y Marcos Carámbula, optó por evitar cuestionar la gestión de Vázquez. Los partidos de oposición, a su vez, al menos hasta el desenlace de las elecciones primarias ( 29 de junio), se concentraron en la competencia interna y dejaron en un segundo plano las críticas al gobierno. Después de junio, blancos, colorados e independientes concentraron sus críticas en el candidato frenteamplista y no en el gobierno saliente. La combinación de estos factores ayuda a explicar la fuerte

3 En plena campaña electoral Vázquez realizó tres actos de "rendición de cuentas" en pequeños pueblos del interior del país: Bella Unión (25/08), Villa Soriano (30/09) y Zapicán (6/10). En estos actos se defendió de las críticas de la oposición y se presentó como líder de izquierda, haciendo énfasis en las políticas sociales realizadas.

$4 \quad$ Además de reunirse con Hillary Clinton (15 de setiembre), Vázquez realizó otras actividades. El 17 se reunió con el Consejo Permanente de la OEA y con el secretario general, José Miguel Insulza. Fue recibido por el presidente del BID (21 de setiembre) y por autoridades del Banco Mundial. El 22 participó en la Sesión de Apertura de la Reunión de Alto Nivel sobre el Cambio Climático en la ONU y el 23 participó en la 64 Asamblea de la ONU.

5 La información sobre el Plan Ceibal puede leerse en http:/ /www.ceibal.org.uy/. La crónica de la entrega de las últimas computadoras portátiles a escolares puede leerse en: http://www.observa.com.uy/actualidad/ nota. $\operatorname{aspx}$ ?id=87197\&ex=25\&ar $=2 \& \mathrm{fi}=1$ 
recuperación de la imagen del Presidente. En un año, desde diciembre de 2008 a diciembre de 2009, la aprobación de la gestión de Vázquez pasó de 49\% a 72\%.

Antes de terminar este apartado es necesario hacer dos precisiones. La primera refiere a posibles explicaciones alternativas a la que se acaba de exponer. Una buena hipótesis rival iría a buscar, en variables económicas, la explicación de la mejora de la aprobación de la gestión del Presidente. La información disponible, como veremos, sugiere que la hipótesis política funciona mejor que la económica. En realidad, los mejores años de la economía uruguaya, durante el primer gobierno del FA, fueron los cuatro primeros. En 2009, el efecto de la crisis financiera de EE.UU. también se hizo sentir en Uruguay. La tasa de crecimiento acumulativo anual del PBI pasó de 8,5\% en 2008 a 2,9\% en el año electoral. ${ }^{6}$ La economía no entró en recesión, pero los indicadores empeoraron significativamente.

La segunda precisión refiere a la estrategia política de Vázquez. No debe inferirse de la narración anterior que, para el líder del FA, el resultado de la elección fuera indiferente. Para Vázquez era muy importante terminar su mandato habiendo incrementado su capital político. Pero también era muy relevante que su partido fuera reelecto. Caminando frecuentemente por el pretil de la violación a la Constitución (que le prohíbe al Presidente usar su investidura para inclinar la balanza a favor de su partido), se las ingenió durante casi todo el 2009 para favorecer la perspectiva de un segundo mandato del FA.

Gráfico 1: Aprobación gestión Presidente Vázquez

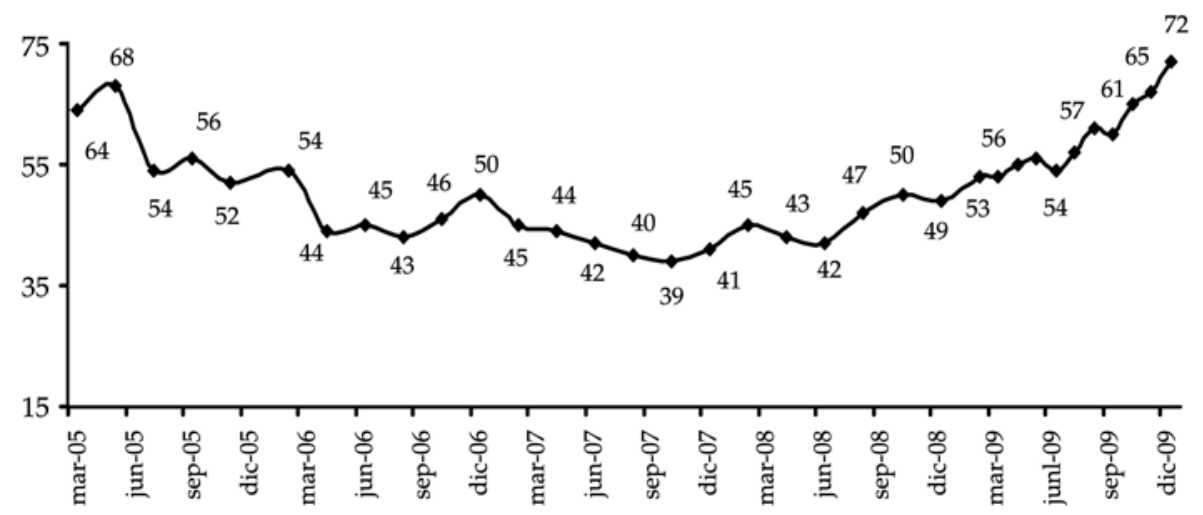

Fuente: Equipos Mori.

\section{Gabinete}

Durante el 2009 fueron removidos de su cargo 7 de los 14 ministros. El primer cambio se verificó el 5 de junio, cuando la ministra del Interior, Daisy Tourné (Partido Socialista), presentó su renuncia. En realidad, Tabaré Vázquez le había pedido abandonar el cargo 
luego de que la ministra realizara duras declaraciones contra dirigentes de la oposición. La información de opinión pública muestra claramente, además, que lo que más le convenía al Presidente era poner una cara nueva en ese ministerio. La ministra venía siendo fuertemente cuestionada por la oposición desde comienzos de 2008. Según los datos de CIFRA, en abril de 2009, 47\% desaprobaban la gestión mientras que apenas el $23 \%$ la aprobaba. Según el mismo sondeo, aproximadamente 8 de cada 10 pensaban en ese momento que la delincuencia había "aumentado mucho" en los últimos dos años, precisamente los años de la gestión de Tourné. ${ }^{7}$ En realidad, el recambio ministerial no se explica por un empeoramiento brusco de los indicadores de percepción de inseguridad. Desde hace muchos años la opinión pública uruguaya demuestra una sensibilidad especial frente a este tema. Por ejemplo, una encuesta realizada por la misma empresa en setiembre de 2008 mostró números similares. ${ }^{8}$ En todo caso, a comienzos de 2009 Vázquez tenía muy claro que Tourné no sólo no había podido modificar el clima de temor en la opinión pública, sino que, además, su estilo político generaba problemas adicionales. El cambio en el Ministerio del Interior le permitió cubrir, hasta el final de su mandato, uno de los flancos más débiles de su gestión.

Los demás cambios en el gabinete siguieron una lógica distinta. Vázquez decidió que aquellos ministros que tuvieran decidido priorizar la lucha electoral deberían dejar sus cargos en el gobierno. Esto obligó a la salida de José Bayardi y Enrique Rubio (candidatos por la Vertiente Artiguista), de Eduardo Bonomi y Ernesto Agazzi (candidatos del MPP) y de Daniel Martínez (candidato por el PS). Para sustituir a Bayardi, a su vez, el Presidente optó por una de sus personas de mayor confianza, Gonzalo Fernández, quien se había desempeñado primero como Secretario de la Presidencia y luego como Canciller. La mayoría de los nuevos ministros asumieron el $1^{\circ}$ de setiembre.

Tabla 1: Gabinete Presidente Tabaré Vázquez

(Segundo semestre 2009)

\begin{tabular}{|c|c|c|c|c|}
\hline Ministerio & Nombre & Sector & Edad & $\begin{array}{l}\text { Formación } \\
\text { académica }\end{array}$ \\
\hline Defensa Nacional & $\begin{array}{l}\text { Gonzalo } \\
\text { Fernández }\end{array}$ & $\begin{array}{l}\text { Partido } \\
\text { Socialista }\end{array}$ & 57 & Abogado \\
\hline Desarrollo Social & $\begin{array}{l}\text { Marina } \\
\text { Arismendi }\end{array}$ & $\begin{array}{l}\text { Partido } \\
\text { Comunista }\end{array}$ & 59 & Maestra \\
\hline $\begin{array}{l}\text { Economía y } \\
\text { Finanzas }\end{array}$ & $\begin{array}{l}\text { Álvaro } \\
\text { García }\end{array}$ & $\begin{array}{l}\text { Partido } \\
\text { Socialista }\end{array}$ & 48 & Contador \\
\hline $\begin{array}{l}\text { Educación y } \\
\text { Cultura }\end{array}$ & $\begin{array}{l}\text { María } \\
\text { Simón }\end{array}$ & Independiente & 55 & $\begin{array}{l}\text { Ingeniera } \\
\text { Industrial }\end{array}$ \\
\hline
\end{tabular}

7 Los datos de la encuesta pueden consultarse en: http://www.cifra.com.uy/novedades.php?idNoticia=61.

8 El sondeo se realizó en setiembre de 2008. Ver: http:/ / www.cifra.com.uy/novedades.php?idNoticia=44. 


\begin{tabular}{|c|c|c|c|c|}
\hline Ministerio & Nombre & Sector & Edad & $\begin{array}{l}\text { Formación } \\
\text { académica }\end{array}$ \\
\hline $\begin{array}{l}\text { Ganadería, } \\
\text { Agricultura y } \\
\text { Pesca }\end{array}$ & $\begin{array}{l}\text { Andrés } \\
\text { Berterreche }\end{array}$ & $\begin{array}{l}\text { Movimiento de } \\
\text { Participación } \\
\text { Popular }\end{array}$ & 47 & $\begin{array}{l}\text { Ingeniero } \\
\text { Agrónomo }\end{array}$ \\
\hline $\begin{array}{l}\text { Industria, } \\
\text { Energía } \\
\text { y Minería }\end{array}$ & $\begin{array}{l}\text { Raúl } \\
\text { Sendic (h). }\end{array}$ & $\begin{array}{l}\text { Compromiso } \\
\text { Frenteamplista }\end{array}$ & 47 & $\begin{array}{l}\text { Licenciado } \\
\text { en Genética } \\
\text { Humana }\end{array}$ \\
\hline Interior & $\begin{array}{l}\text { Jorge } \\
\text { Bruni }\end{array}$ & Independiente & 58 & Abogado \\
\hline $\begin{array}{l}\text { Relaciones } \\
\text { Exteriores }\end{array}$ & Pedro Vaz & $\begin{array}{l}\text { Partido } \\
\text { Socialista }\end{array}$ & 47 & Abogado \\
\hline Salud Pública & $\begin{array}{l}\text { María Julia } \\
\text { Muñoz }\end{array}$ & Independiente & 59 & Médica \\
\hline $\begin{array}{l}\text { Trabajo y } \\
\text { Seguridad } \\
\text { Social }\end{array}$ & Julio Baraibar & $\begin{array}{l}\text { Movimiento de } \\
\text { Participación } \\
\text { Popular }\end{array}$ & 55 & \\
\hline $\begin{array}{l}\text { Transporte y } \\
\text { Obras Públicas }\end{array}$ & Víctor Rossi & $\begin{array}{l}\text { Alianza } \\
\text { Progresista }\end{array}$ & 65 & \\
\hline $\begin{array}{l}\text { Turismo y } \\
\text { Deporte }\end{array}$ & Héctor Lescano & $\begin{array}{l}\text { Alianza } \\
\text { Progresista }\end{array}$ & 60 & Veterinario \\
\hline $\begin{array}{l}\text { Vivienda, } \\
\text { Ordenamiento } \\
\text { Territorial y } \\
\text { Medio Ambiente }\end{array}$ & Carlos Colacce & Independiente & 49 & $\begin{array}{l}\text { Ingeniero } \\
\text { Civil }\end{array}$ \\
\hline $\begin{array}{l}\text { Oficina de } \\
\text { Planeamiento } \\
\text { y Presupuesto }\end{array}$ & $\begin{array}{l}\text { Martín } \\
\text { Dibarboure }\end{array}$ & Independiente & 47 & Contador \\
\hline
\end{tabular}

Fuente: Elaboración propia a partir de información publicada en prensa.

\subsection{Legislación}

La centralidad de la lucha electoral en el escenario político no impidió que el proceso legislativo arrojara al menos tres productos de indudable relevancia política: relaciones laborales, financiamiento de los partidos y descentralización y ley de cuotas.

\section{Negociación colectiva}

Actores y especialistas consideraban impostergable la aprobación de una norma que regulara las relaciones laborales para, por un lado, colmar el vacío legal existente y, por el otro, abatir los elevados niveles de desconfianza entre los actores (Rodríguez, Cozzano y Mazzuchi, 2007: 213-214). A iniciativa del Frente Amplio, y luego de intensas y complejas negociaciones con los partidos de oposición y con los actores sociales (cámaras empresariales y sindicatos de trabajadores), fue votada una nueva ley de negociación 
colectiva, por la que se crea un "Sistema de Relaciones Laborales" (Ley 18.566). La ley cumplió el primer objetivo pero no el segundo. Las cámaras empresariales se opusieron al proyecto por considerar que consagra el "sesgo a favor de los sindicatos" que, según los empresarios, caracterizó al gobierno de Vázquez. Por eso mismo, las asociaciones empresariales presentaron una querella ante la OIT. Las cámaras, más específicamente, manifestaron dos objeciones a la ley. La primera refiere a la conformación de un Consejo Superior Tripartito, con nueve miembros del Poder Ejecutivo, seis de los sindicatos y seis de los empresarios. Los empresarios consideran que la existencia de esta institución viola el principio de negociación libre, voluntaria y bipartita consagrado por la OIT. Además, no están de acuerdo con asignar al gobierno autoridad definitoria en las controversias entre empresarios y trabajadores (al margen de las condiciones de trabajo). La segunda gran objeción está relacionada con la falta de regulación de la actividad sindical en la ley. La incorporación, durante el trámite parlamentario, de una cláusula de paz (acordada por senadores blancos y frenteamplistas) permitió que la ley fuera aprobada con los votos del oficialismo y del Partido Nacional (en adelante PN).

\section{Financiamiento de los partidos}

Uruguay también tenía pendiente, hacía muchos años, modernizar la legislación sobre partidos, especialmente en lo relacionado con el financiamiento. Aunque la norma aprobada con el apoyo de todos los partidos (Ley 18.485) no conforma plenamente a los especialistas, representa un punto de inflexión significativo en la regulación del financiamiento de los partidos (Chasquetti, 2010). La nueva ley regula el financiamiento de las campañas electorales pero también la actividad política permanente de los partidos. Para ambas actividades la norma formula un sistema mixto, que combina el financiamiento público (tradicionalmente regulado en Uruguay con leyes ad hoc votadas antes de cada elección) con el financiamiento privado (aportes de militantes y donaciones). La ley fija topes para las donaciones y establece que, por encima de cierto monto, las contribuciones deben ser nominativas. La nueva norma establece mecanismos claros de rendición de cuentas, transparencia y sanciones. Otra innovación importante de la ley es la referencia a las fundaciones partidarias. La norma intenta consolidar la tendencia a la formación de fundaciones de partidos o sectores que se ha verificado en los últimos años en el sistema de partidos uruguayo. Al mismo tiempo, se pretende asegurar que estas fundaciones cumplan efectivamente el papel de think tanks y no operen, meramente, como pantallas para la captación de recursos.

\section{Descentralización y participación}

La aprobación de la Ley de Descentralización y Participación (Ley 18.567 y modificativas) representa un cambio mayor en términos de la arquitectura de las instituciones políticas uruguayas. Esta ley, aprobada con los votos de legisladores del FA y del Partido Nacional, estableció un tercer nivel de gobierno: los municipios. Hasta la aprobación de esta norma en Uruguay existían solamente dos niveles de gobierno: el gobierno nacional y los 19 gobiernos departamentales (el Intendente y la Junta Departamental). De acuerdo al texto de la ley, el objetivo es crear municipios en todas las ciudades que cuenten al menos con 
2.000 habitantes. Tomando nota de los problemas de implementación generados por un cambio institucional de esta magnitud, para la elección de 2010 se decidió constituir autoridades municipales solamente en aquellos centros poblados que tengan un mínimo de 5.000 habitantes. ${ }^{9}$

Los municipios son órganos integrados por cinco miembros denominados concejales distribuidos por representación proporcional integral (artículo $9^{\circ}$ ). Según la ley, el concejal más votado se denominará Alcalde, presidirá el municipio (artículo $11^{\circ}$ ) y será el único concejal remunerado. No está permitido votar concejales de un partido y autoridades departamentales de otro. De todas maneras es muy probable que, después de las elecciones departamentales y municipales del 9 de mayo de 2010, en algunos departamentos el partido político del intendente municipal no coincida con el de todos los alcaldes de su departamento. Esto representará un paso importante hacia la construcción de sistemas políticos departamentales más pluralistas y competitivos. Las alcaldías pueden transformarse en una plataforma de lanzamiento para políticos que quieran desafiar la hegemonía de los intendentes departamentales. La nueva ley es un avance hacia la necesaria dispersión del poder político en la dimensión territorial.

Tabla 2: Municipios por departamento

\begin{tabular}{lclc}
\hline Departamento & Municipios & Departamento & Municipios \\
\hline Canelones & 29 & Soriano & 2 \\
Maldonado & 8 & Durazno & 2 \\
Montevideo & 8 & Tacuarembó & 2 \\
Colonia & 6 & Treinta y Tres & 2 \\
Salto & 6 & Cerro Largo & 2 \\
Rocha & 4 & Florida & 2 \\
Artigas & 3 & Río Negro & 2 \\
Rivera & 3 & San José & 2 \\
Paysandú & 3 & Flores & 1 \\
Lavalleja & 2 & & \\
\hline
\end{tabular}

Total de municipios que se elegirán en todo el país el 9 de mayo 2010

Fuente: http://www.corteelectoral.gub.uy/gxpsites/hgxpp001.aspx.

9 De acuerdo al texto de la ley: “ARTÍCULO 24.- En todas las poblaciones de más de 5.000 habitantes se instalarán estos Municipios a partir del año 2010. Las restantes que estén comprendidas en el inciso segundo del artículo $1^{\circ}$ de esta ley, lo harán a partir del año 2015. En los departamentos donde existan menos de dos Municipios electivos en el año 2010, se incluirán las localidades inmediatamente siguientes en orden decreciente -de acuerdo con su cantidad de población- hasta completar la cifra de dos por departamento, sin incluir la capital departamental. Dichas localidades deberán cumplir los requisitos establecidos en el inciso segundo del artículo $1^{\circ}$ de la presente ley". 


\section{Ley de cuotas}

En mayo de 2009 fue aprobada la Ley 18.476 que establece, por primera vez en la historia electoral uruguaya, un mecanismo que obliga a tomar en cuenta el género de los candidatos. El proyecto original fue presentado el 8 de marzo de 2006 por legisladores del Frente Amplio. De acuerdo a esta iniciativa, a partir de la entrada en vigencia de esta norma, todos los candidatos que se presenten para competir en las diferentes etapas del proceso electoral (nacional, departamental y local) deberían "incluir en su integración personas de ambos sexos, con un mínimo de un tercio de candidatos correspondiente al sexo que lleve menor número de éstos". Esta cuota debería cumplirse tanto para titulares como para los suplentes. Por implicar un cambio en las normas electorales, el proyecto requería una mayoría especial de $2 / 3$. Aunque la acción de las organizaciones feministas y, muy especialmente, de la Bancada Bicameral Femenina, logró, al cabo de muchos años, poner en evidencia la existencia de serios obstáculos a la participación de la mujer en política en Uruguay y persuadir a una parte de la cúpula de los partidos respecto a la necesidad de incorporar mecanismos de acción afirmativa, el proyecto, tal como había sido presentado, no tenía suficiente apoyo. En mayo de 2008 el Senado (por una amplia mayoría de 28 en 30) aprobó un proyecto distinto que fue ratificado, un año después, por la Cámara de Diputados. En esencia, se estableció que la cuota "regiría para las elecciones internas de los partidos políticos y para la elección de sus órganos ejecutivos a partir de 2009 sin límite de tiempo". Pero se hizo una modificación fundamental: "para los cargos de representación nacional y departamental (...) la ley regirá recién para el ciclo electoral 2014-2015 y por única vez quedando supeditada su continuidad a la evaluación de esa legislatura" (Johnson y Pérez 2010: 36). La ley, a pesar de sus obvias limitaciones, es un paso adelante.

\section{ELECCIONES PRIMARIAS: TRES REVOLUCIONES}

Las elecciones primarias se realizaron el domingo 28 de junio. Más allá de la entidad de los procesos legislativos en marcha y de los, ya referidos, exitosos esfuerzos de Tabaré Vázquez para reponerse de los golpes de fines de 2008, la competencia por la candidatura presidencial dentro de los tres principales partidos ocupó el lugar central en la agenda pública durante el primer semestre de 2009.

\subsection{Los resultados en cada partido}

La elección de junio determinó cambios importantes en los tres partidos. En el FA, José Mujica venció al candidato auspiciado por el Presidente y la mayoría de las fracciones. En el PN, Luis Alberto Lacalle logró recuperarse de la dura derrota sufrida ante Jorge Larrañaga en 2004 y recuperar la mayoría dentro del partido. En el PC, la elección de junio marcó el fin de la hegemonía de Julio María Sanguinetti y Jorge Batlle, y la consolidación del ascendente liderazgo de Pedro Bordaberry. 
Tabla 3: Votos en las primarias del FA, PN y PC por candidato

\begin{tabular}{llc}
\hline Partido & \multicolumn{1}{c}{ Candidato } & $\begin{array}{c}\text { Porcentaje } \\
(\%)\end{array}$ \\
\hline \multirow{3}{*}{ Frente Amplio } & José Mujica & 52 \\
& Danilo Astori & 40 \\
Partido Nacional & Marcos Carámbula & 8 \\
& Luis A. Lacalle & 57 \\
Partido Colorado & Jorge Larrañaga & 43 \\
& Pedro Bordaberry & 72 \\
& José Amorín Batlle & 15 \\
& Luis Hierro López & 12 \\
\hline
\end{tabular}

Fuente: Zuasnábar (2009).

\section{La "revolución plebeya" de José Mujica}

En el FA comparecieron tres candidatos: José Mujica, Danilo Astori y Marcos Carámbula. De los tres, Marcos Carámbula fue el último en decidirse a competir y el que menos apoyo tuvo entre las fracciones frenteamplistas. El primero en proclamar su precandidatura había sido Danilo Astori. Tuvo el apoyo de una amplia coalición interna conformada por la mayoría de las fracciones (Asamblea Uruguay, Partido Socialista, Alianza Progresista y Nuevo Espacio). En términos ideológicos, apoyaron al ex ministro de Economía y Finanzas los grupos más centristas de la coalición. José Mujica, por su parte, contó con el apoyo del ala izquierda del FA (Movimiento de Participación Popular, Corriente de Acción y Pensamiento - Libertad, Partido Comunista y Partido por la Victoria del Pueblo). Una forma sencilla de ilustrar las diferencias existentes entre los tres candidatos es presentar el número de senadores que respaldaban a cada uno de los candidatos: 8 con Astori, 7 con Mujica y 2 con Carámbula. La candidatura de Astori tuvo una importantísima ventaja adicional. Durante todo el año 2008 contó con el apoyo, público y reiterado, del presidente Vázquez.

A pesar de la potencia de la coalición "astorista", Mujica no tuvo mayores dificultades para derrotar al ex Ministro de Economía. Como puede verse en el gráfico, Mujica logró ser más popular que Astori durante casi todo el mandato de Vázquez. La imagen de Astori sufrió dos golpes fuertes: durante el 2006, el impulso al TLC con EE.UU. (que lo debilitó entre los frenteamplistas) y, durante el 2007, la aprobación de la reforma tributaria (que fue muy resistida por la oposición, que insistió en denunciar que el nuevo sistema tributario significaba un duro golpe al "bolsillo" de la clase media). Astori se recuperó levemente durante la campaña electoral para las primarias, cuando comenzó a abandonar el discurso técnico y adoptó la retórica de un candidato de izquierda.

Mientras Astori pagaba el precio de liderar la reforma más impopular del gobierno de Vázquez (la implantación del Impuesto a la Renta de las Personas Físicas) y de argumentar a favor de un TLC con EE.UU. (contradiciendo el tradicional recelo respecto 
Gráfico 2: Popularidad de Mujica y Astori

(Saldos netos simpatía-antipatía)

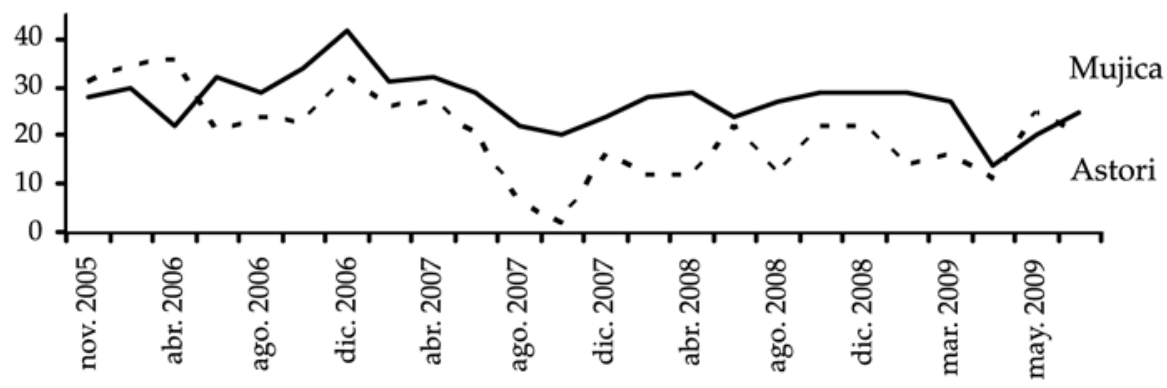

Fuente: Equipos Mori.

al librecomercio de la izquierda uruguaya), Mujica se las ingenió para sintonizar con el cambiante humor del electorado frenteamplista. Generalmente apoyó las posiciones de Vázquez, pero no vaciló en tomar distancia del Presidente en temas muy importantes (como la política respecto a la inseguridad) y en canalizar la frustración del núcleo duro de militantes y electores frenteamplistas, desconformes con el pacto Vázquez-Astori. Vázquez construyó su liderazgo en el FA diferenciándose de Astori y asumiendo la defensa de la tradición ideológica frenteamplista, pero gobernó convirtiendo a su ex rival en su principal aliado, de hecho, en una suerte de primer ministro. Además, consciente de sus principales flancos débiles, en marzo de 2009 Mujica hizo anuncios muy importantes. Renunció al Movimiento de Participación Popular (MPP) ${ }^{10}$ y comunicó que su modelo, tanto en términos políticos como desde el punto de vista del manejo de la economía, no era Chávez sino Lula. ${ }^{11}$

\section{La "restauración" de Lacalle}

Si el triunfo de Mujica sobre Astori, desafiando a la mayoría de la "aristocracia" dirigente del FA, evoca las revoluciones plebeyas, el de Lacalle sobre Larrañaga en el Partido Nacional tuvo cierto aire a restauración borbónica. En la primaria de 2004, Lacalle fue derrocado por una amplia coalición interna encabezada por el senador Jorge Larrañaga. La victoria del ex intendente de Paysandú sobre el ex presidente fue categórica: dos de cada tres

10 Este anuncio procuró desactivar uno de los principales temores de una parte de la opinión pública acerca de Mujica: sus vínculos con la estructura orgánica del MLN-Tupamaros: “a mi vieja barra le digo adiós".

11 Mujica buscó sistemáticamente asociar su imagen a la de Lula. Presentó al gobierno de Lula como su modelo en términos políticos para insistir en su vocación de "negociar, negociar y negociar". Presentó el manejo de la economía del gobierno de Lula como su modelo para aventar cualquier temor de un manejo irresponsable de las cuentas públicas. Levantar la figura de Lula fue una de sus maneras de decir claramente que no se proponía llevar a Uruguay por el camino de las “izquierdas populistas". Se pueden reconstruir fácilmente los temas de la campaña de Mujica porque la página Web de su campaña todavía funciona. Ver: http://www. pepetalcuales.com.uy/. La lectura de los breves artículos firmados por el propio Mujica permite tener una noción del estilo de comunicación y de los temas elegidos. 
votantes votaron por el líder emergente. Desde mediados de 2004 a comienzos de 2008, algunos dirigentes herreristas intentaron evitar que Lacalle procurara, nuevamente, ser el candidato de esta fracción en la primaria. La maniobra fracasó, en parte por la falta de coordinación entre los tres aspirantes a la sucesión (el senador Luis Alberto Heber y los intendentes departamentales Juan Chiruchi y Carmelo Vidalín), y en parte por la vigencia del propio Lacalle que, de acuerdo a los resultados de las encuestas, seguía siendo el político preferido por los electores herreristas. A comienzos de 2008, Lacalle anunció que daría nuevamente la batalla por la candidatura presidencial. Los tres frustrados postulantes a la precandidatura presidencial por el herrerismo asumieron actitudes diferentes. Vidalín se alejó del sector, Chiruchi se mostró agraviado (pero permaneció en la fracción) y Heber aceptó con resignación la decisión del experimentado líder del sector. Rápidamente, Lacalle volvió a poner de manifiesto su ingenio. Tejió una alianza electoral con la tercera fracción en importancia dentro del PN, Correntada Wilsonista. El senador Francisco Gallinal, líder de esta tendencia, había sido uno de los aliados más importantes en la coalición antilacallista conformada por Larrañaga en la elección anterior. En el contexto de la conformación de este entendimiento electoral, denominado Unidad Nacional, Lacalle comenzó un proceso sistemático de viraje hacia el centro. La retórica liberal que lo caracterizara a lo largo de su carrera política se fue asordinando y cediendo paso a un creciente énfasis en los problemas y políticas sociales. El cambio discursivo no le impidió seguir confrontando con el gobierno frenteamplista en temas muy relevantes como la seguridad ciudadana, el gasto público o la reforma tributaria.

Por su parte, Larrañaga también movió las piezas. Durante años había sido el más duro de los críticos del gobierno de Vázquez. A comienzos de 2008, pensando en instalarse en el centro del espectro político, comenzó a enviar señales de entendimiento hacia el FA. A medida que la campaña electoral fue avanzando, Larrañaga envió señales cada vez más confusas acerca de quiénes eran sus amigos y quiénes sus adversarios en el sistema político. En lugar de proponerle a los blancos un camino para desplazar al FA del gobierno, fue insinuando su intención de compartir el gobierno con la izquierda. En cambio, Lacalle, insistió en presentarse como portador de un proyecto alternativo al del FA: No intentó mimetizarse con el FA. Para Lacalle la oposición tiene que ser diferente al gobierno: "Nosotros representamos una visión alternativa, que viene de "alter" que en latín quiere decir otro. El alter ego es mi otro yo. Y el Partido Nacional, que es la alternativa, debe asumir el contenido de esta palabra. Tiene que ser distinto, suficientemente separado en su propuesta, para que la gente tenga ante sí una opción; no un matiz".

La combinación de los aciertos de Lacalle con los desconcertantes movimientos de Larrañaga generó un escenario altamente competitivo en la primaria del PN. Al igual que en el FA, en el PN el desafiante se fue convirtiendo en favorito. En febrero de 2009, el promedio de las encuestas mostraba que el líder del herrerismo ya había logrado superar al de Alianza Nacional. Esta tendencia se mantuvo durante los meses siguientes. Larrañaga intentó corregir el rumbo de la campaña. Dejó de lado la estrategia de la "coalición nacional" y pasó a confrontar dura y directamente con Mujica. ${ }^{12}$ El resultado

12 Durante las últimas semanas de la campaña Larrañaga hizo declaraciones fuertes contra Mujica: “un gobierno de Mujica no respetaría la libertad"; "Mujica hace simplificaciones al mejor estilo de Cantinflas"; "si gana Mujica Uruguay será una provincia de Argentina"; "fue el peor Ministro de Ganadería de la historia del país"; "es el gran simplificador del sistema político". 
de la elección puso de manifiesto que el ajuste de la estrategia fue tardío. Lacalle se impuso con una diferencia muy clara: $57 \%$ contra $43 \%$.

\section{Bordaberry y el "nuevo Partido Colorado"}

La primaria del Partido Colorado (en adelante PC) fue la menos competitiva de las tres. A lo largo de toda la campaña todos los intentos realizados por instalar una precandidatura alternativa a la de Bordaberry fracasaron estruendosamente. Ninguna de las dos fracciones más importantes del PC durante las últimas dos décadas (la Lista 15 y el Foro Batllista, encabezadas respectivamente por los ex presidentes Jorge Batlle y Julio María Sanguinetti) pudo lograr que sus candidatos (José Amorín Batlle por la 15 y Luis Hierro López por el Foro) levantaran vuelo. La victoria de Pedro Bordaberry fue la más rotunda de todas. Obtuvo 73\% de los votos, contra 15\% de Amorín Batlle y 12\% de Hierro López.

No por previsible la victoria de Bordaberry fue intrascendente. También en el caso del PC, la primaria abrió un escenario nuevo. Desde 1985 hasta 2009, Sanguinetti y Batlle, sin perjuicio de competir ardorosamente entre sí, compartieron la hegemonía del partido. Sanguinetti no pudo ignorar a Batlle durante sus dos presidencias. Batlle no tuvo más remedio que pactar con Sanguinetti durante la suya. La victoria de Bordaberry marca un punto de inflexión. Se terminó el ciclo de Sanguinetti y Batlle. El PC comienza una nueva etapa. El discurso de Bordaberry tiene diferencias claras con el de los líderes referidos. Hay menos ideología y más pragmatismo, menos teoría y más gerencialismo, menos confrontación y más consensualismo. Bordaberry subraya todo el tiempo estas diferencias pero no lo hace agraviando a los ex presidentes.

Gráfico 3: Posición de los principales precandidatos en el eje izquierda-derecha (2009)

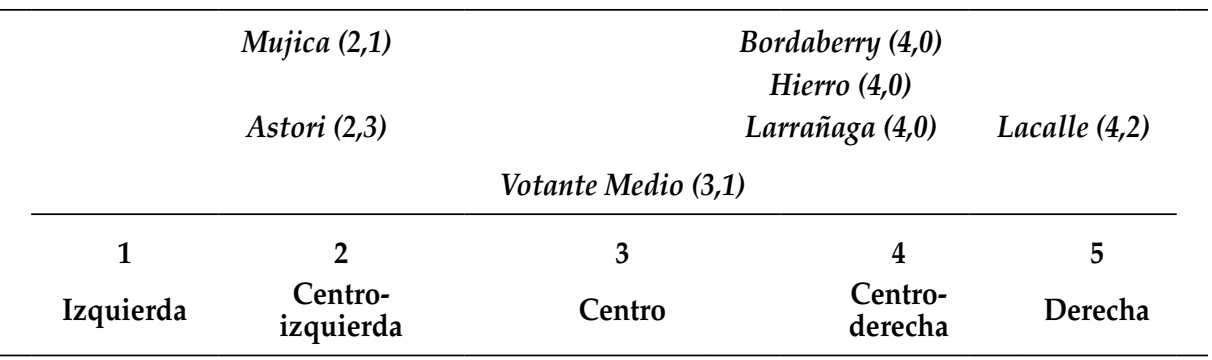

Fuente: Equipos Mori: http:/ / www.equipos.com.uy/noticia/izquierda-y-derecha-los-candidatosy-los- ciudadanos/.

En suma, en los tres ganaron los candidatos que lograron interpretar mejor las preferencias de cada una de estas tradiciones políticas. En los tres casos, triunfaron los líderes de perfil más fuerte. En el caso del FA y del PN, los dos partidos que, de acuerdo a la serie de encuestas, estaban llamados a disputar la elección nacional, fueron electos los candidatos menos centristas. En la escala izquierda-derecha de 5 puntos (en la que 1 es izquierda y y 5 derecha), según los datos de Equipos Mori, en el momento de la elección primaria la posición de Mujica era 2,1 contra 2,3 de Astori, y la de Lacalle 4,0, contra 4,2 de Larrañaga. 
Este resultado rarifica la paradoja señalada por Colomer (2002). Una regla de selección de candidatos presidenciales inclusiva puede conspirar contra el desempeño electoral del partido. Las primarias abiertas favorecen la elección de candidatos con preferencias alejadas de las del votante medio. Como se verá un poco más adelante, los tres partidos tuvieron plena conciencia de este fenómeno y obraron en consecuencia.

\subsection{La tasa de participación}

Los resultados de las primarias en cada partido no sorprendieron al sistema político uruguayo. En realidad, el triunfo de Mujica, Lacalle y Bordaberry era considerado como el escenario más probable por las principales empresas encuestadoras del país. En cambio, llamó la atención de analistas y protagonistas el nivel de participación de la ciudadanía en la elección por ser menor tanto a lo estimado por las encuestadoras como al registrado en las dos experiencias anteriores. En la elección primaria, a diferencia de las elecciones nacionales, el voto no es obligatorio. Antes de la elección primaria, los expertos en comportamiento electoral se inclinaban a pensar que la existencia de escenarios de competencia no triviales en todos los partidos, y muy especialmente en los dos más poderosos (FA y PN), incentivaría la participación de la ciudadanía en la elección. Si en el año 2004, a pesar de no haber competencia en el FA (Astori prefirió no desafiar a Vázquez), el nivel de participación había sido de casi 46\% (ver Gráfico 4), cabía esperar que junio de 2009 la fuerte competencia entre Mujica y Astori en el FA determinaría un aumento significativo de la tasa de participación de los ciudadanos. Sin embargo, la tasa de participación fue aun menor que la de 2004 (44,5\%). Como cinco años antes, quienes (en mayor proporción) volvieron a faltar a la cita fueron los electores frenteamplistas. Como en junio de 2004, la interna que más votantes movilizó fue la del PN (ver Gráfico 5).

La relativamente baja tasa de participación de los frenteamplistas puede explicarse por dos razones. En primer lugar, el clima de expectativas en la opinión pública conspiraba contra la participación electoral. Según los datos de Factum, casi 8 de cada 10 votantes del FA, a comienzos de junio, pensaba que José Mujica ganaría la primaria. ${ }^{13}$ Para entender esto hay que tomar en cuenta, entre otras circunstancias, que Danilo Astori sufrió un importante quebranto de salud a fines de mayo que le impidió hacer campañna durante las últimas cinco semanas previas a la elección primaria. En segundo lugar, según los datos elaborados por Zuasnábar (2009), la baja tasa de participación de los frenteamplistas se explicaría, fundamentalmente, por la comparativamente baja tasa de votación de quienes preferían a Mujica. El perfil sociodemográfico del votante de Mujica (edad, nivel educativo), a su vez, ayudaría a explicar este comportamiento electoral. Efectivamente, la diferencia a favor de Mujica en la primaria ( $52 \%$ a $40 \%$ ) terminó siendo sensiblemente menor a la proyectada por las encuestas. El promedio de las encuestas sugería que Mujica tenía más de 20 puntos de ventaja sobre Astori $(57 \%$ a $36 \%) .{ }^{14}$

13 El 78\%, exactamente, según la información presentada por Oscar Bottinelli en el programa En Perspectiva de radio Espectador, el viernes 12 de junio de 2009. Disponible en: http:/ /www.factum.edu.uy/

14 La información sobre las encuestas previas puede verse en Zuasnábar (2009). 
Gráfico 4: Participación electoral

(\% habilitados para votar)

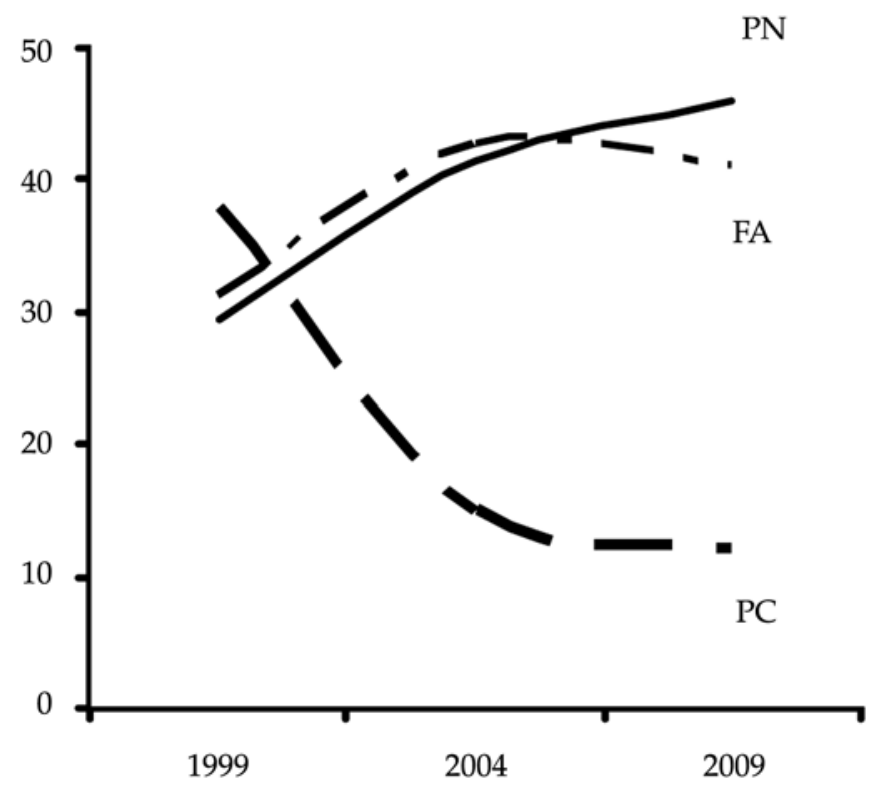

Fuente: Zuasnábar (2009).

Gráfico 5: Participación por partidos

(\% total de votantes)

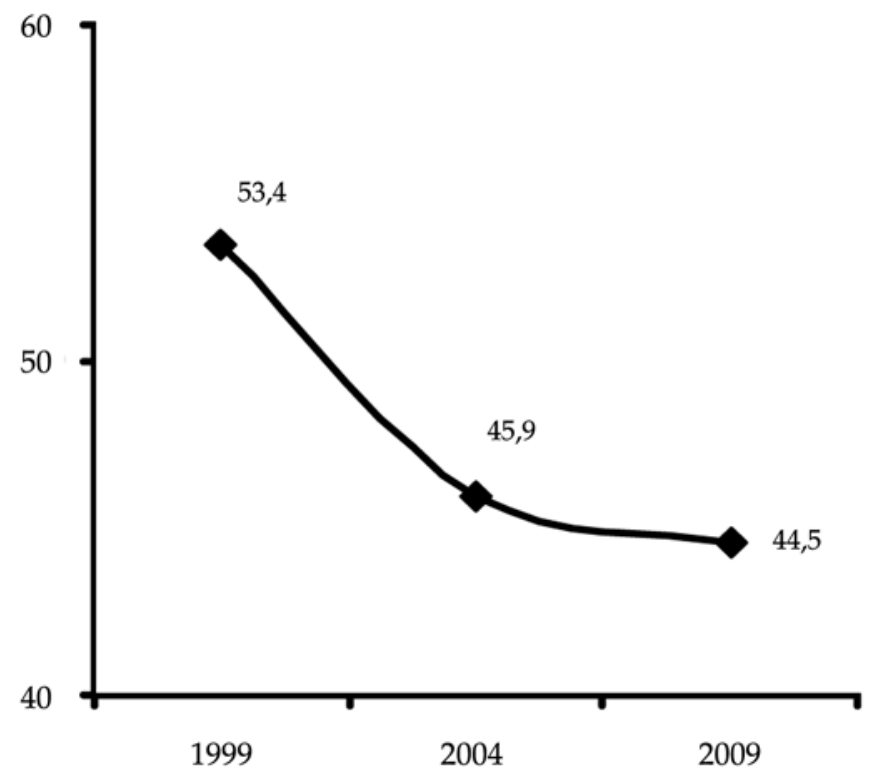

Fuente: Zuasnábar (2009). 


\section{ELECCIONES NACIONALES}

\subsection{La elección presidencial y parlamentaria de octubre}

\section{La campaña electoral hacia la primera vuelta}

Después de la elección primaria, el FA, el PN y el PC enfrentaron tres desafíos comunes. El primero de ellos era el de suturar las heridas internas generadas por la lucha electoral. El enfrentamiento entre los precandidatos fue, en algunos momentos de la campaña, muy duro. Astori sembró dudas acerca de qué podría pasar con el gobierno de la economía durante una presidencia de Mujica. ${ }^{15}$ Larrañaga hizo alusiones a las denuncias de corrupción durante el gobierno de Lacalle. Hierro dudó en voz alta de las convicciones democráticas de Pedro Bordaberry. Los partidos saben que los electores se retraen cuando un partido muestra fisuras internas importantes. El segundo desafío de los tres partidos consistía en evitar la fuga de votos de los simpatizantes de los candidatos derrotados. Para el FA era esencial evitar la pérdida de votos "astoristas", para el PN retener a los "wilsonistas" y para el PC a los "batllistas". El tercer desafío postprimarias era el de conquistar el centro. En Uruguay, la distribución del electorado en el eje izquierda-derecha es normal. Los partidos saben que maximizan su votación cuando logran crecer en el "nicho" de electores centristas. En los tres partidos habían triunfado los precandidatos menos centristas. Los tres candidatos, Mujica, Lacalle y Bordaberry, debían encontrar formas de tender puentes hacia el centro.

Gráfico 6: Distribución del electorado según autoidentificación ideológica (1999-2009)

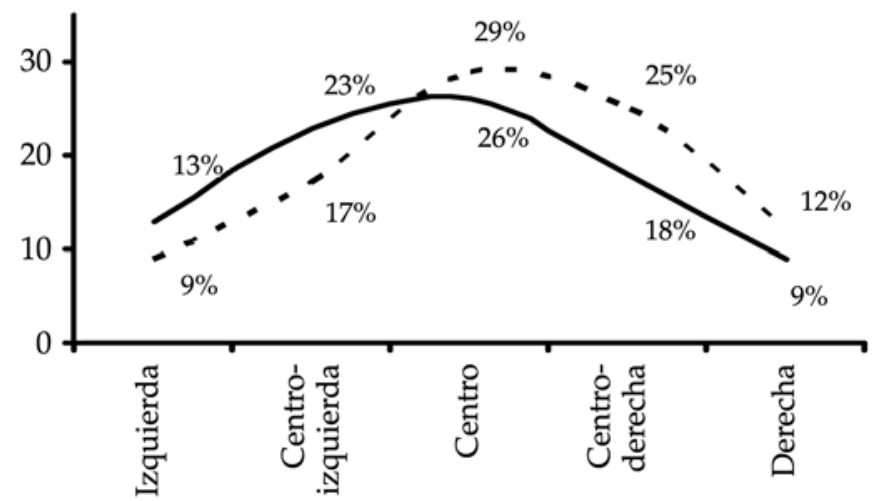

Fuente: Zuasnábar (2009). 
Para los tres, la manera más sencilla de resolver los tres desafíos era, simplemente, completar la fórmula presidencial con el segundo más votado. Una fórmula presidencial compuesta por el primero y el segundo ayudaría a reparar las grietas en la imagen del partido, a retener a los electores del vencido y a desplazar al partido hacia el centro. Lacalle fue el primero en tomar este camino. Lo hizo la noche misma de la elección primaria. Larrañaga, contra muchos pronósticos, aceptó el ofrecimiento y la fórmula del PN quedó acordada de inmediato. La velocidad del movimiento político generó un alto impacto en los medios de comunicación y dejó al PN en ventaja en la carrera hacia octubre. En el FA la construcción del acuerdo entre Mujica y Astori dio más trabajo pero se concretó antes de que se cumplieran las dos semanas de la elección primaria. La incorporación de Astori en la fórmula fue muy importante para la candidatura de Mujica. Es difícil imaginar un dúo integrado por dos políticos tan distintos y, por eso mismo, tan complementarios: el "caudillo" y el "doctor", el hombre de pueblo ${ }^{16}$ y el universitario, el que genera confianza en los pobres y el que despierta simpatía entre los empresarios. El único que apostó a una estrategia diferente, para completar la fórmula presidencial, fue Bordaberry. La contundencia de su victoria en la primaria le dio espacio suficiente como para ensayar otra solución. En lugar de apelar a un político de carrera, convocó a un Hugo de León, mucho más conocido por su brillante trayectoria como futbolista (en el Club Nacional de Fútbol y la selección uruguaya) que por su fervorosa simpatía y, hasta entonces, discretísima militancia en el PC.

Lacalle se adelantó a sus rivales en la resolución del problema de la fórmula presidencial. Pero, mientras reconstruía su relación con Astori, Mujica tomó la ofensiva en el debate público. Muy rápidamente quedó claro que el candidato frenteamplista no perdería la oportunidad de golpear a Lacalle en su flanco más débil: las denuncias de corrupción contra funcionarios de su gobierno (1990-1994). ${ }^{17}$ De todos modos, la campaña del FA no se basó solamente en este issue. Desde principios de julio, los dirigentes frenteamplistas descubrieron que muchas declaraciones de Lacalle podían ser fácilmente ridiculizadas, o bien porque, lisa y llanamente, eran equivocadas, o porque podían ser presentadas ante la opinión pública como "errores" sin mayor esfuerzo. ${ }^{18}$ Lacalle no solamente tuvo que defenderse de las críticas de la fórmula frenteamplista. Muy a menudo sus dichos fueron cuestionados por figuras de primer nivel del gobierno. Por otro lado, y pese a la virulencia de la campaña hasta junio, la fórmula frenteamplista logró mostrarse, rápidamente, como un equipo sin fisuras. Astori adquirió

16 Una de las principales fortalezas de la imagen de Mujica es, precisamente, que la ciudadanía lo percibe como un político "cercano", "sensible a los problemas de la gente", "capaz de escuchar".

17 El 8 de julio Mujica visitó la Bolsa de Valores. Aprovechó la ocasión para martillar en ese mismo clavo. Un periodista le preguntó si, de ser electo presidente, impulsaría una reforma constitucional "a lo Chávez". La respuesta de Mujica fue fulminante: Declaraciones de Mujica al salir de la Bolsa de Valores: "Acá no hay que hacer una reforma para evitar a los Chávez; hay que hacer una reforma para evitar a los chorros".

18 Apenas un ejemplo. El 13 de julio, en un acto en la ciudad de Paysandú, dijo Lacalle: "El gasto público será lo primero que atenderemos cuando lleguemos al gobierno (...) vamos a entrar con una motosierra". La reacción del FA fue demoledora. La Ministra de Desarrollo Social declaró que la propuesta de Lacalle implicaba recortar drásticamente el gasto social. 
un gran protagonismo ${ }^{19}$ Para reforzar la imagen de Mujica como "presidenciable", como es usual, también la campaña del FA apeló al recurso de los viajes al exterior. En agosto visitó a Lula y Bachelet y en setiembre se reunió con las principales figuras de la política argentina. La andanada de críticas puso a Lacalle a la defensiva durante buena parte de la campaña electoral. Cuando pasaron a la ofensiva, focalizaron sus ataques al candidato del FA en su imagen y en cuestionar su aptitud para ejercer el cargo presidencial. ${ }^{20}$

Bordaberry aprovechó la creciente tensión del enfrentamiento entre blancos y frenteamplistas para posicionarse en el lugar del político moderado, dialoguista, conciliador. Este posicionamiento generó un problema importante al Partido Independiente, que venía cultivando el perfil de "puente" entre los dos bloques históricamente enfrentados (blancos y colorados de un lado, Frente Amplio del otro). El candidato a vicepresidente, Hugo de León, adquirió un papel relevante. Basó su discurso en convocar a los colorados a "volver a casa". Para decodificar este discurso hay que tener presente que, entre la elección de 1999 y la de 2004, el PC perdió dos de cada tres votantes.

\section{Resultados}

- Votación por partido

La primera vuelta de las elecciones nacionales se realizó el domingo 25 de octubre. Votó el $89,91 \%$ de los habilitados. Las encuestas anunciaban que el resultado más probable era que el FA no superaría el $50 \%$ de votos emitidos y que, por ende, sería necesaria una segunda vuelta. Efectivamente, el FA obtuvo el $47,96 \%$ de los votos emitidos. Como las bancas en el parlamento se asignan a partir de los votos válidos, el FA retuvo la mayoría parlamentaria. Esto determinó que el 30 de noviembre se llevara a cabo el balotaje entre Mujica y Lacalle.

Tabla 4: Representación parlamentaria por partido

\begin{tabular}{|c|c|c|c|c|c|c|c|c|}
\hline \multirow[b]{2}{*}{ Elección } & \multicolumn{4}{|c|}{ Senadores } & \multicolumn{4}{|c|}{ Diputados } \\
\hline & FA & PN & PC & $\begin{array}{c}\mathrm{UC} / \mathrm{NE} / \\
\mathrm{PI}\end{array}$ & FA & PN & PC & $\begin{array}{c}\mathrm{UC} / \mathrm{NE} / \\
\mathrm{PI}\end{array}$ \\
\hline 1984 & 6 & 11 & 14 & 0 & 21 & 35 & 41 & 2 \\
\hline 1989 & 7 & 13 & 9 & 2 & 21 & 39 & 30 & 9 \\
\hline 1994 & 9 & 10 & 11 & 1 & 31 & 31 & 32 & 5 \\
\hline 1999 & 12 & 7 & 11 & 1 & 40 & 22 & 33 & 4 \\
\hline 2004 & 17 & 11 & 3 & 0 & 52 & 36 & 10 & 1 \\
\hline 2009 & 17 & 9 & 5 & 0 & 50 & 30 & 17 & 2 \\
\hline
\end{tabular}

Fuente: Corte Electoral.

19 Astori, que durante muchos años cultivó un perfil conciliador, no vaciló en enfrentarse con Lacalle. El 27 de agosto criticó severamente las declaraciones de la fórmula blanca sobre el déficit fiscal: el Partido Nacional, dijo, opina con "ignorancia o mala fe. Yo no tengo derecho acusarlos de mala fe, por lo tanto los acuso de ignorantes y de ineptos para manejar los temas económicos".

20 Dijo Larrañaga: "Mujica no está capacitado para ser presidente". 
Gráfico 7: Votos por partido, 1984-2009

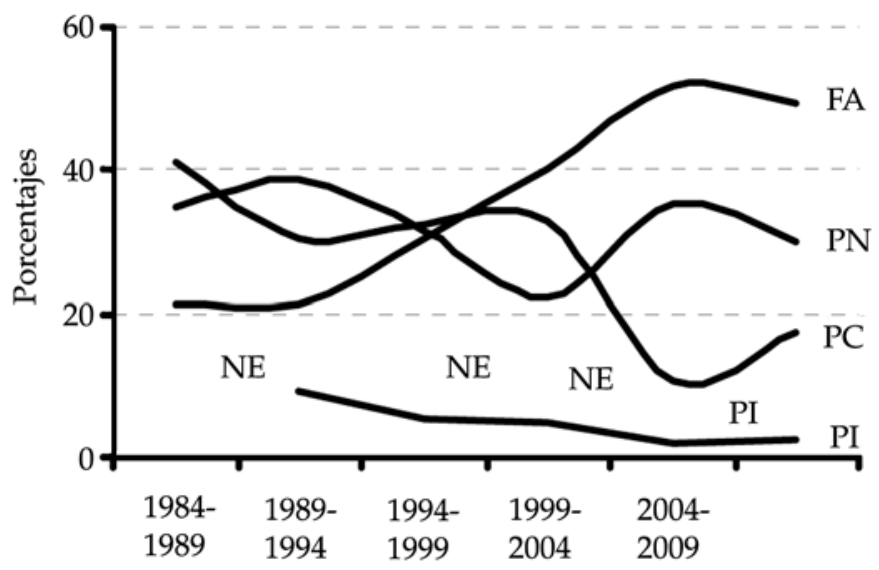

Fuente: Elaboración propia con información de la Base de Datos PRI-ICP-FCS-UdelaR.

Gráfico 8: Volatilidad electoral, 1984-2009

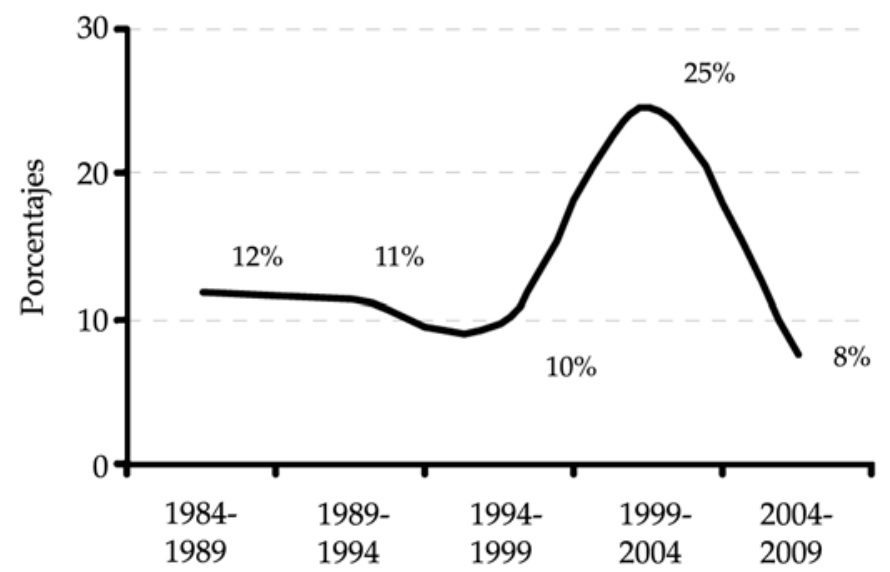

Fuente: Elaboración propia con información de la Base de Datos PRI-ICP-FCS-UdelaR.

Antes de analizar los resultados del balotaje es necesario extraer algunas conclusiones de la elección de octubre. En primer lugar, en términos porcentuales, por primera vez en veinte años el FA perdió votos. Había venido creciendo sin solución de continuidad 
desde 1989. El FA pasó de 51,7\% a 49,3\% de los votos válidos. Tomando en cuenta que el FA sigue captando más votos que los demás partidos entre los nuevos votantes, Gustavo De Armas calcula que, en realidad, la pérdida real de votos entre 2004 y 2009 fue de aproximadamente 4\% del total de votos emitidos en 2009 (2009: 52).

En segundo lugar, se registró el nivel más bajo de volatilidad electoral desde la restauración de la democracia hasta la fecha $(8 \%)$. Como puede verse en el Gráfico 8 es particularmente llamativo el contraste entre el comportamiento de los electores en 2009 respecto a 2004. Desde este punto de vista, el comportamiento electoral de 2009, en cambio, es semejante al verificado en 1989, 1994 y 1999.

En tercer lugar, el único partido que logró crecer fue el PC. También el PN perdió votos respecto a 2004. El PC no logró alcanzar al PN, pero su representación parlamentaria creció significativamente: pasó de 3 a 5 senadores y de 10 a 17 diputados. Esta votación consolidó el liderazgo de Pedro Bordaberry y confirmó el potencial del nuevo líder colorado para crecer en el espacio que va desde el centro hasta la derecha.

En cuarto lugar, el Partido Independiente (PI) no alcanzó su principal objetivo político que era conquistar una banca en el Senado. La elección de 2009 volvió a mostrar lo difícil que es consolidar una oferta electoral centrista. El protagonismo de Astori, Larrañaga y el discurso componedor de Bordaberry dejaron muy poco espacio para una oferta centrista.

En quinto lugar, Asamblea Popular (AP) tampoco logró su meta de obtener al menos una banca en la Cámara de Representantes. La candidatura de Mujica, en la medida en que revivió la esperanza de un "giro a la izquierda" durante un eventual segundo mandato del FA, asfixió la propuesta de izquierda radical.

En sexto lugar, la recuperación del PC y el fracaso de las propuestas del PI y de AP determinaron un crecimiento, significativo pero moderado, de la fragmentación del sistema de partidos. Aunque hay cuatro partidos con representación parlamentaria (el PI obtuvo dos diputados), el NEP sigue siendo levemente inferior a tres (ver Gráficos 9 y 10).

En séptimo lugar, el FA pasó a ser el partido más votado en la mayoría de los departamentos. En 1999 ganó en 4 . En el 2004 en 7. En 2009, en 11 de los 19 departamentos. En esta elección el FA pasó al primer lugar en el ranking en algunos lugares del país que parecían bastiones inexpugnables de los partidos tradicionales como Río Negro, Colonia y San José (ver Tabla 5).

En octavo lugar, el FA, a su vez, perdió apoyo en ocho departamentos. Como puede verse en la Tabla 6, las mayores pérdidas en términos porcentuales se registraron en algunos departamentos especialmente importantes como Montevideo y Maldonado.

En noveno lugar, llama la atención que las mayores tasas de crecimiento en la votación al FA se registraron en los departamentos del norte del país, como Artigas, Tacuarembó, Rivera y Salto. 
Gráfico 9: Número efectivo de partidos electoral (1984-2009)

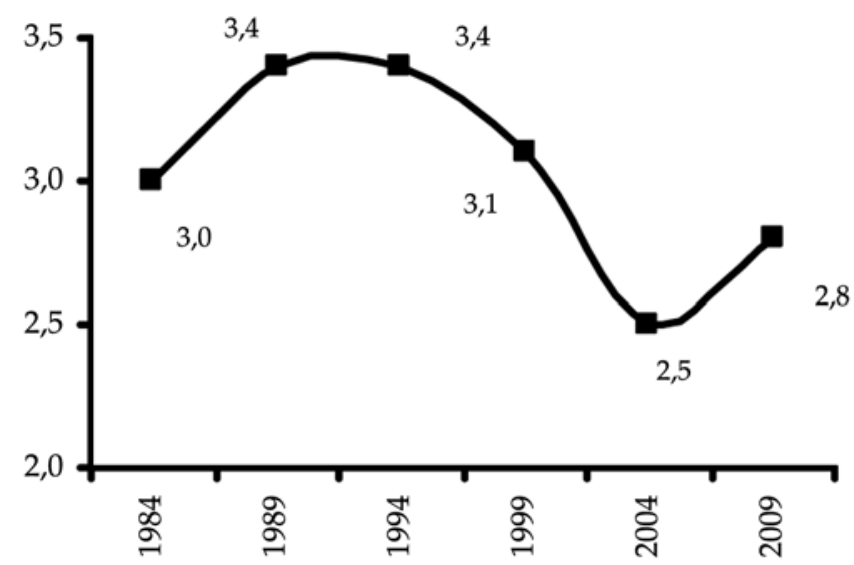

Fuente: Cardarello (2009).

Gráfico 10: Número efectivo de partidos parlamentario (1984-2009)

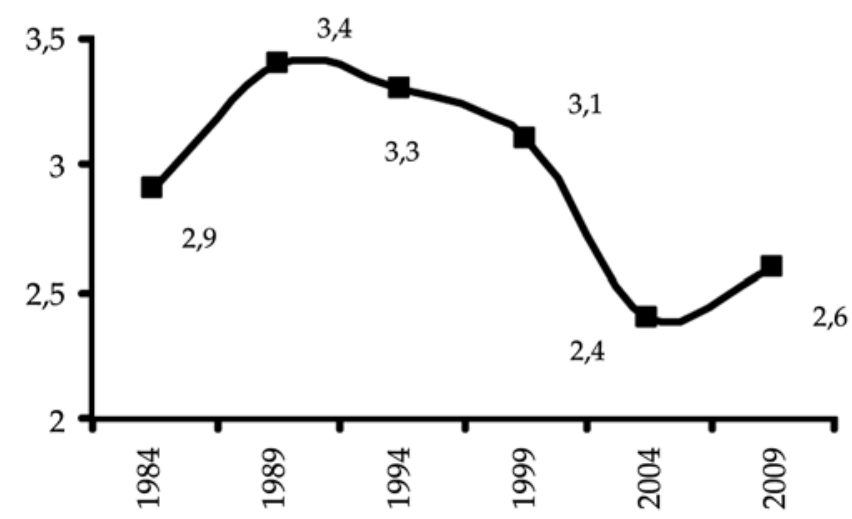

Fuente: Cardarello (2009).

Tabla 5: Votos válidos por partido y por departamento

\begin{tabular}{lccccc}
\hline Departamento & $\begin{array}{c}\text { Frente } \\
\text { Amplio } \\
(\%)\end{array}$ & $\begin{array}{c}\text { Partido } \\
\text { Nacional } \\
(\%)\end{array}$ & $\begin{array}{c}\text { Partido } \\
\text { Colorado } \\
(\%)\end{array}$ & $\begin{array}{c}\text { Partido } \\
\text { Independiente } \\
(\%)\end{array}$ & $\begin{array}{c}\text { Asamblea } \\
\text { Popular } \\
(\%)\end{array}$ \\
\hline Montevideo & 57,7 & 22,4 & 15,4 & 3,5 & 1,1 \\
Canelones & 52,9 & 29,1 & 14,8 & 2,5 & 0,8 \\
Maldonado & 42,2 & 32,6 & 22,0 & 3,0 & 0,3 \\
Rocha & 42,8 & 35,0 & 19,9 & 1,7 & 0,5 \\
\hline
\end{tabular}




\begin{tabular}{lccccc}
\hline \multicolumn{1}{c}{ Departamento } & $\begin{array}{c}\text { Frente } \\
\text { Amplio } \\
(\%)\end{array}$ & $\begin{array}{c}\text { Partido } \\
\text { Nacional } \\
(\%)\end{array}$ & $\begin{array}{c}\text { Partido } \\
\text { Colorado } \\
(\%)\end{array}$ & $\begin{array}{c}\text { Partido } \\
\text { Independiente } \\
(\%)\end{array}$ & $\begin{array}{c}\text { Asamblea } \\
\text { Popular } \\
(\%)\end{array}$ \\
\hline Treinta y Tres & 39,1 & 44,4 & 14,8 & 1,3 & 0,3 \\
Cerro Largo & 41,1 & 43,6 & 14,0 & 1,0 & 0,3 \\
Rivera & 34,8 & 36,2 & 27,9 & 1,0 & 0,2 \\
Artigas & 37,8 & 42,0 & 19,2 & 0,8 & 0,2 \\
Salto & 47,5 & 27,7 & 23,1 & 1,5 & 0,3 \\
Paysandú & 47,0 & 36,0 & 14,8 & 1,8 & 0,4 \\
Río Negro & 41,6 & 31,2 & 25,4 & 1,6 & 0,3 \\
Soriano & 45,0 & 31,1 & 22,0 & 1,5 & 0,4 \\
Colonia & 39,4 & 36,5 & 21,4 & 2,4 & 0,2 \\
San José & 44,1 & 36,3 & 17,0 & 2,0 & 0,6 \\
Flores & 31,6 & 45,3 & 21,4 & 1,3 & 0,4 \\
Florida & 39,4 & 37,1 & 20,8 & 2,3 & 0,5 \\
Durazno & 35,7 & 42,7 & 19,2 & 2,1 & 0,3 \\
Lavalleja & 31,6 & 42,8 & 23,0 & 2,3 & 0,3 \\
Tacuarembó & 38,2 & 43,1 & 17,0 & 1,5 & 0,3 \\
Interior & 43,6 & 35,0 & 19,0 & 2,0 & 0,4 \\
Total & 49,3 & 29,9 & 17,5 & 2,6 & 0,7 \\
\hline
\end{tabular}

Fuente: Base de datos PRI-ICP-FCS-UdelaR.

Tabla 6: Evolución de la votación del FA por departamento (\% de votos válidos)

\begin{tabular}{lrrrrrrrr}
\hline \multicolumn{1}{c}{ Departamento $\left(^{*}\right)$} & $\begin{array}{r}1971 \\
(\%)\end{array}$ & $\begin{array}{r}1984 \\
(\%)\end{array}$ & $\begin{array}{r}1989 \\
(\%)\end{array}$ & $\begin{array}{c}1994 \\
(\%)\end{array}$ & $\begin{array}{c}1999 \\
(\%)\end{array}$ & $\begin{array}{c}2004 \\
(\%)\end{array}$ & $\begin{array}{c}2009 \\
(\%)\end{array}$ & $\begin{array}{c}2009-2004 \\
(\%)\end{array}$ \\
\hline Artigas & 7,9 & 6,1 & 5,1 & 13,5 & 22,7 & 32,8 & 37,8 & 5,1 \\
Tacuarembó & 9,1 & 8,0 & 6,6 & 13,4 & 22,4 & 33,4 & 38,2 & 4,8 \\
Rivera & 7,6 & 6,4 & 5,4 & 9,3 & 19,5 & 30,7 & 34,8 & 4,0 \\
Salto & 10,7 & 10,2 & 8,5 & 20,9 & 31,6 & 44,5 & 47,5 & 3,0 \\
Cerro Largo & 6,9 & 6,3 & 5,7 & 14,2 & 26,8 & 39,0 & 41,1 & 2,1 \\
Durazno & 8,0 & 5,4 & 5,9 & 12,1 & 21,9 & 33,9 & 35,7 & 1,7 \\
Río Negro & 12,7 & 9,5 & 10,7 & 18,0 & 29,0 & 40,6 & 41,6 & 1,0 \\
Soriano & 10,2 & 10,5 & 10,1 & 21,8 & 33,3 & 44,2 & 45,0 & 0,8 \\
Paysandú & 13,2 & 14,5 & 10,4 & 27,3 & 42,2 & 46,3 & 47,0 & 0,6 \\
Treinta y Tres & 7,3 & 5,6 & 4,7 & 12,2 & 23,2 & 38,6 & 39,1 & 0,5 \\
Promedio interior & 9,6 & 10,3 & 9,9 & 19,5 & 31,1 & 43,9 & 43,6 & $-0,2$ \\
Flores & 7,8 & 4,9 & 7,9 & 13,9 & 21,7 & 32,5 & 31,6 & $-0,9$ \\
Lavalleja & 7,0 & 5,1 & 5,1 & 11,8 & 21,1 & 32,6 & 31,6 & $-1,0$ \\
Canelones & 11,3 & 15,8 & 16,7 & 27,9 & 39,3 & 54,6 & 52,9 & $-1,8$ \\
Rocha & 6,1 & 6,6 & 6,0 & 13,5 & 28,4 & 45,4 & 42,8 & $-2,6$ \\
\hline
\end{tabular}




\begin{tabular}{lrrrrrrrr}
\hline \multicolumn{1}{c}{ Departamento $\left(^{*}\right)$} & $\begin{array}{r}1971 \\
(\%)\end{array}$ & $\begin{array}{c}1984 \\
(\%)\end{array}$ & $\begin{array}{c}1989 \\
(\%)\end{array}$ & $\begin{array}{c}1994 \\
(\%)\end{array}$ & $\begin{array}{c}1999 \\
(\%)\end{array}$ & $\begin{array}{c}2004 \\
(\%)\end{array}$ & $\begin{array}{c}2009 \\
(\%)\end{array}$ & $\begin{array}{c}2009-2004 \\
(\%)\end{array}$ \\
\hline Florida & 8,5 & 9,1 & 9,3 & 18,6 & 29,0 & 42,2 & 39,4 & $-2,8$ \\
Colonia & 11,2 & 12,1 & 11,4 & 20,2 & 30,0 & 42,5 & 39,4 & $-3,1$ \\
Montevideo & 30,1 & 33,7 & 34,5 & 44,1 & 51,8 & 62,7 & 57,7 & $-4,9$ \\
Maldonado & 9,5 & 11,3 & 11,5 & 18,8 & 35,6 & 49,1 & 42,2 & $-6,9$ \\
Total & 18,3 & 21,3 & 21,2 & 30,6 & 40,1 & 51,7 & 49,3 & $-2,3$ \\
\hline
\end{tabular}

Fuente: Base de Datos PRI-ICP-FCS-UdelaR. Ordenado de mayor a menor por crecimiento del FA desde 2004 a 2009.

\section{- Votación por fracción}

La votación de octubre confirmó las tendencias que se manifestaran en las primarias. Las fracciones lideradas por Mujica, Lacalle y Bordaberry fueron las más votadas. En el FA, por primera vez en su historia electoral, una fracción logró mantenerse en el primer lugar en el ranking interno en dos elecciones consecutivas. Hasta el 2009, la hegemonía en la interna había ido desplazándose cada cinco años hacia un nuevo sector. En el PN y el PC, en cambio, la mayoría cambió de manos. El herrerismo (de Lacalle) desplazó a Alianza Nacional (de Larrañaga). En el PC, el batllismo fue categóricamente derrotado por el sector de Bordaberry (Vamos Uruguay).

Tabla 7: $\quad$ Desempeño de las fracciones del FA

\begin{tabular}{lcc}
\hline \multicolumn{1}{c}{ Fracción (lista al Senado) } & Porcentaje & Senadores \\
\hline Espacio 609 & 33,61 & 6 \\
Frente Líber Seregni (astoristas) $\left(^{*}\right)$ & 27,19 & $5+1$ \\
Partido Socialista & 14,69 & 2 \\
Corriente de Acción y Pensamiento - Libertad $\left(^{* *}\right)$ & 6,9 & 1 \\
Partido Comunista de Uruguay & 6,45 & 1 \\
Vertiente Artiguista & 4,83 & \\
Lista 5005 $\left(^{* * *}\right)$ & 2,39 & \\
Espacio Frenteamplista & 2,12 & \\
Lista 711 (Por la senda de Sendic) & 1,23 & \\
Otros & 0,59 & $17\left(^{* * * *}\right)$ \\
Total & 100 & \\
\hline
\end{tabular}

Fuente: Base de Datos PRI-ICP-FCS-UdelaR.

Notas: $\left({ }^{*}\right)$ El FLS es un sublema que reúne a la mayoría de los grupos que apoyaron a Astori en la primaria. ${ }^{* *}$ CAP-L son escindidos del MPP que responden al liderazgo del ex guerrillero Eleuterio Fernández Huidobro. $\left(^{* * *}\right)$ La 5005 es una lista conformada en torno a dos de los ministros más notoriamente leales al presidente Vázquez (Víctor Rossi y María Julia Muñoz). En la primaria adhirieron a Marcos Carámbula $\left(^{* * * *}\right) 16$ senadores electos más el vicepresidente Astori del FLS. 
Tabla 8: Desempeño de las fracciones del PN

\begin{tabular}{lcc}
\hline \multicolumn{1}{c}{ Fracción (lista al Senado) } & Porcentaje & Senadores \\
\hline Unidad Nacional $\left(^{*}\right)$ & 51,86 & 5 \\
Alianza Nacional $\left(^{* *}\right)$ & 41,2 & 4 \\
Coraje Wilsonista $\left.{ }^{* * *}\right)$ & 5,52 & \\
Otros & 1,42 & \\
Total & 100 & 9 \\
\hline
\end{tabular}

Fuente: Base de Datos PRI-ICP-FCS-UdelaR.

Notas: $\left({ }^{*}\right)$ Sublema de la coalición entre el Herrerismo (de Lacalle) y Correntada Wilsonista (sector del senador Francisco Gallinal). ${ }^{* *}$ Fracción liderada por el senador Jorge Larrañaga. $\left({ }^{* * *}\right)$ Sector conformado por el dirigente del departamento de Canelones Alberto Perdomo. Se escindieron de Alianza Nacional durante el proceso de conformación de la lista al senado de Alianza Nacional.

Tabla 9: Desempeño de las fracciones del PC

\begin{tabular}{lcc}
\hline \multicolumn{1}{c}{ Fracción (lista al Senado) } & Porcentaje & Senadores \\
\hline Vamos Uruguay $\left(^{*}\right)$ & 55,99 & 3 \\
Propuesta Batllista (Proba) $\left(^{* *}\right)$ & 30,33 & 2 \\
Uruguay es posible $\left(^{* * *}\right)$ & 7,76 & \\
Más $\left.{ }^{* * * *}\right)$ & 5,05 & \\
Otros & 0,87 & 5 \\
Total & 100 & \\
\hline
\end{tabular}

Fuente: Base de Datos PRI-ICP-FCS-UdelaR.

Notas: $\left.{ }^{*}\right)$ Fracción liderada por Bordaberry. $\left.{ }^{* *}\right)$ Alianza de algunos dirigentes provenientes de los sectores de Jorge Batlle (lista 15) y Julio María Sanguinetti (Foro Batllista). Sus figuras principales son el actual senador José Amorín Batlle y los ex intendentes Tabaré Viera y Eduardo Malaquina. $\left({ }^{* * *}\right)$ Sector liderado por Alberto Iglesias, que asume la defensa del legado del pachequismo. $\left.{ }^{* * * *}\right)$ Sector encabezado por el ex ministro Martín Aguirrezabala. Muy cercanos al ex presidente Jorge Batlle.

Tabla 10: Número efectivo de fracciones

\begin{tabular}{ccccccc}
\hline & \multicolumn{2}{c}{ Partido Colorado } & \multicolumn{2}{c}{ Partido Nacional } & \multicolumn{2}{c}{ Frente Amplio } \\
\cline { 2 - 7 } Elección & Electoral & $\begin{array}{c}\text { Parlamen- } \\
\text { tario }\end{array}$ & Electoral & $\begin{array}{c}\text { Parlamen- } \\
\text { tario }\end{array}$ & Electoral & $\begin{array}{c}\text { Parlamen- } \\
\text { tario }\end{array}$ \\
\hline 1984 & 2,4 & 2,3 & 2,1 & 1,8 & 3,7 & 2,6 \\
1989 & 3,7 & 2,5 & 3,6 & 2,9 & 3,3 & 2,3 \\
1994 & 3,1 & 1,9 & 5,1 & 4,2 & 4,9 & 3,5 \\
1999 & 2,2 & 2,0 & 2,0 & 1,7 & 5,7 & 4,8 \\
2004 & 2,5 & 1,8 & 2,6 & 2,5 & 6,1 & 4,6 \\
2009 & 2,4 & 1,9 & 2,3 & 2,0 & 4,5 & 3,8 \\
\hline
\end{tabular}

Fuente: Cardarello (2009). 


\subsection{El balotaje}

El PN comenzó la campaña hacia el balotaje recibiendo dos noticias desalentadoras. La primera de ellas la recibió la noche misma de la elección nacional. Pedro Bordaberry anunció que votaría por Lacalle en el balotaje pero no comprometió el apoyo militante de su partido a la candidatura del candidato del PN. Esta actitud fue muy diferente a la asumida por el PN 10 años antes, cuando el PN, luego de negociar con el PC, decidió orgánicamente hacer campaña por la candidatura de Jorge Batlle. Bordaberry parece haber valorado que sería muy difícil asegurar que una parte importante de sus electores votara por el ex presidente Batlle y que la probabilidad de victoria de Lacalle tendía a cero (a ningún líder en ascenso le interesa apoyar una causa perdida). La segunda mala noticia llegó dos días después de la elección nacional. En ese momento se supo que el FA, una vez escrutados los votos observados, obtendría la mayoría en ambas cámaras. Los blancos se vieron enfrentados a un gran desafío político. Debían encontrar un argumento razonable para pedir el voto a Lacalle cuando era público y notorio que el FA tendría el control del Parlamento. La solución que hallaron fue ingeniosa: armaron una estrategia electoral apoyada en el concepto de equilibrio entre poderes ("El equilibrio está en tus manos", proponía el eslogan lanzado por el equipo de la campaña de Lacalle). Al mismo tiempo, volvieron a reclamar, en vano, la realización de debates entre los candidatos a la presidencia.

Esta estrategia duró una semana. El domingo $1^{\circ}$ de noviembre, un principio de incendio (de origen incierto) en una casa de Montevideo permitió descubrir un importante arsenal privado (cerca de 700 armas, entre ellas, aproximadamente 200 armas largas). El dueño del arsenal murió combatiendo contra las fuerzas policiales. El tipo de armamento encontrado (la mayoría armas viejas) y algunos documentos instalaron, de inmediato, la hipótesis de una "conexión política". El comando electoral del PN decidió abandonar la estrategia inicial y explotar la pregunta, que en voz baja o en voz alta, muchos se hicieron: ¿tendría el MLN-Tupamaros alguna conexión con ese arsenal ${ }^{21}$ La bancada del PN decidió interpelar a los ministros de Defensa y del Interior para darle la mayor repercusión a estas especulaciones. El "caso Feldman" ocupó el centro de la campaña durante las primeras dos semanas de la campaña. Promediando el mes de noviembre, una vez más, la campaña del PN cambió de rumbo. Nadie había logrado documentar la supuesta conexión con el MLN-T y las encuestas mostraron que el operativo de campaña estaba siendo un boomerang. ${ }^{22}$ Los blancos, con resignación, retomaron la estrategia inicial.

El balotaje se realizó el 29 de noviembre. La fórmula Mujica-Astori se impuso cómodamente sobre la de Lacalle-Larrañaga (cerca de 200.000 votos de diferencia, un poco menos del $10 \%$ del total de votos emitidos). Mujica fue más votado que Lacalle en solamente cinco departamentos. Pero la diferencia obtenida en Montevideo y Canelones, las dos principales

21 El MLN-T sigue existiendo. Se sigue definiendo como Organización Político-Militar. Sobre el complejo proceso de adaptación del MLN-T a la legalidad y la competencia electoral ver Garcé (2006).

22 Un sondeo de CIFRA, divulgada el 12 de noviembre, mostró que el $49 \%$ de los encuestados tenía decidido votar por Mujica contra un $40 \%$ de Lacalle. El trabajo de campo había sido realizado entre el 7 y 9 de noviembre, en pleno apogeo del "caso Feldman". 
circunscripciones electorales, fue decisiva (cerca de 270.000 votos de ventaja para Mujica en estos dos departamentos).

Tabla 11: Votación en el balotaje por departamento

\begin{tabular}{|c|c|c|c|c|}
\hline \multirow{2}{*}{ Departamento } & \multicolumn{2}{|c|}{ Mujica - Astori } & \multicolumn{2}{|c|}{ Lacalle - Larrañaga } \\
\hline & Votos & $\%$ & Votos & $\%$ \\
\hline Montevideo & 552.578 & 59,79 & 332.232 & 35,95 \\
\hline Canelones & 180.138 & 55,68 & 130.099 & 40,21 \\
\hline Maldonado & 50.314 & 46,36 & 53.110 & 48,94 \\
\hline Rocha & 24.107 & 45,49 & 26.252 & 49,53 \\
\hline Treinta y Tres & 15.434 & 42,16 & 19.875 & 54,29 \\
\hline Cerro Largo & 28.190 & 45,89 & 31.147 & 50,7 \\
\hline Rivera & 29.677 & 41,01 & 39.930 & 55,17 \\
\hline Artigas & 21.823 & 42,48 & 28.133 & 54,77 \\
\hline Salto & 44.375 & 52,02 & 37.944 & 44,48 \\
\hline Paysandú & 39.123 & 48,9 & 37.865 & 47,33 \\
\hline Río Negro & 17.263 & 45,81 & 18.899 & 50,15 \\
\hline Soriano & 30.521 & 48,86 & 29.164 & 46,69 \\
\hline Colonia & 39.763 & 43,53 & 47.993 & 52,54 \\
\hline San José & 33.644 & 47,08 & 34.866 & 48,79 \\
\hline Flores & 7.477 & 38,1 & 11.253 & 57,35 \\
\hline Florida & 22.196 & 43,51 & 26.612 & 52,16 \\
\hline Durazno & 17.160 & 40,57 & 23.581 & 55,75 \\
\hline Lavalleja & 16.664 & 35,81 & 27.928 & 60,01 \\
\hline Tacuarembó & 27.191 & 40,51 & 37.627 & 56,06 \\
\hline Total & 1.197 .638 & 52,39 & 994.510 & 43,51 \\
\hline
\end{tabular}

Fuente: Banco de Datos PRI-ICP-FCS.

Mujica venció a Lacalle por un amplio margen (más de 200.000 votos). Lacalle no pudo obtener el respaldo del total de quienes votaron al PN y al PC. Si lo hubiera logrado, hubiera obtenido 1.062.251. La información de opinión pública difundida durante la campaña sugiere que había una parte del electorado colorado (aproximadamente 1 de cada 10 según Grupo Radar) que no quería votar por Lacalle. También había un pequeño grupo de ciudadanos que, habiendo votado al PN en octubre, anunciaba su intención de apoyar a Mujica ( $6 \%$ de los votantes blancos según la misma encuesta). Los votantes del PI, por su parte, se dividían tercios entre Mujica, Lacalle y el voto en blanco. ${ }^{23}$ 


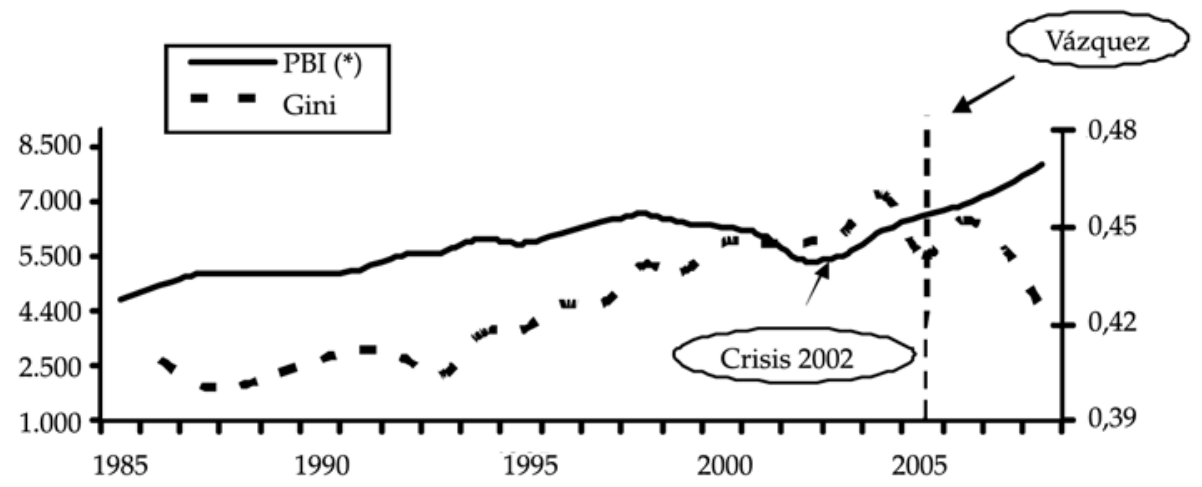

Fuente: Gustavo De Armas (2009).

Nota: PBI per cápita a valores constantes (US\$2.000).

\subsection{Algunas hipótesis sobre el resultado electoral}

En definitiva, luego de una campaña electoral compleja, el FA logró retener la presidencia y la mayoría absoluta. No es difícil entender la reelección del FA cuando se toman en cuenta algunos datos del contexto económico y social. El PBI mantuvo la expansión iniciada después de la crisis de 2002. La distribución del ingreso mejoró durante los últimos años del gobierno de Vázquez, especialmente a partir de la entrada en vigencia del nuevo Sistema de Salud. La desocupación cayó de 12,1 a comienzos de 2005 a 8,3\% a medidados de 2009, y el ingreso de los hogares aumentó un 35\% acumulado entre principios de 2005 de 2009 (De Armas 2009). La pobreza cayó desde 32\% en 2005 al 22\% en 2008 (Bango, 2009). La inversión extranjera directa alcanzó niveles inéditos. La evolución del resultado del sector público fue similar a la del promedio de los gobiernos anteriores (1985-2004) y consistente con el objetivo de retener el gobierno (ver Gráfico 12).

Un poco más difícil, en todo caso, es entender por qué, en un contexto tan favorable, el FA no logró mantener su votación de 2004. Para buscar una explicación a esa pregunta hay que explorar, al menos, dos hipótesis. En primer lugar, está fuera de discusión que la imagen personal de Mujica ofrecía importantes flancos débiles: su pasado guerrillero, su "torpe aliño indumentario", ${ }^{24}$ su lenguaje, más cercano al lunfardo que al de un presidente convencional. En segundo lugar, puede haber conspirado contra su desempeño electoral su posicionamiento en eje izquierda-derecha durante una parte de la campaña. Mujica, más durante el 2008 que durante el 2009, le ofreció a la opinión pública un segundo gobierno del FA, "más de izquierda" que el de Vázquez. En tercer lugar, hay que tener presente que la historia electoral uruguaya enseña que, como norma general, como puede verse en el Gráfico 14, el partido de gobierno no logra mantener su base electoral (Altman, Cardarello y Garcé, 1999). Es posible que la tradicional virulencia de la competencia política en Uruguay sea la variable que mejor explica el virtualmente inevitable desgaste electoral de los partidos de gobierno. 
Gráfico 12: Resultado global sector público

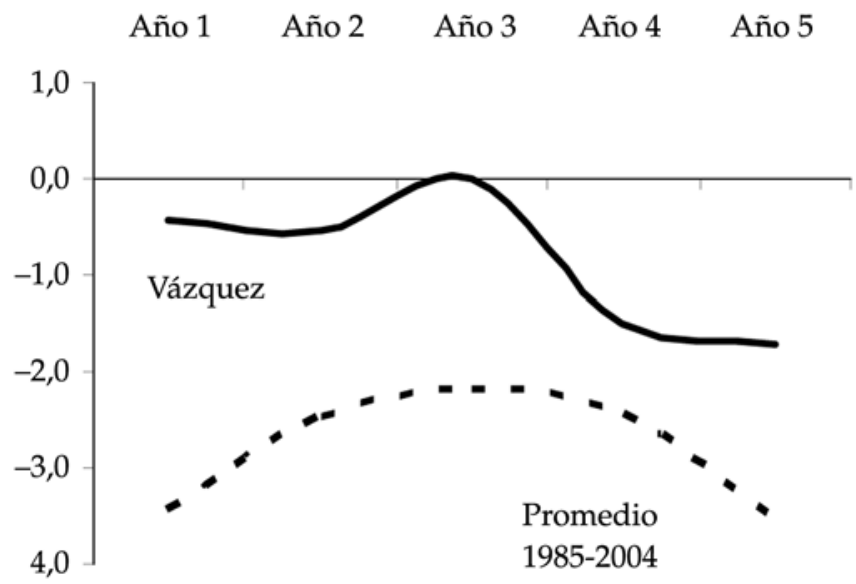

Fuente: Área de Coyuntura - Instituto de Economía - Freya - UdelaR.

Gráfico 13: Inversión extranjera directa

(Como \% del PBI)

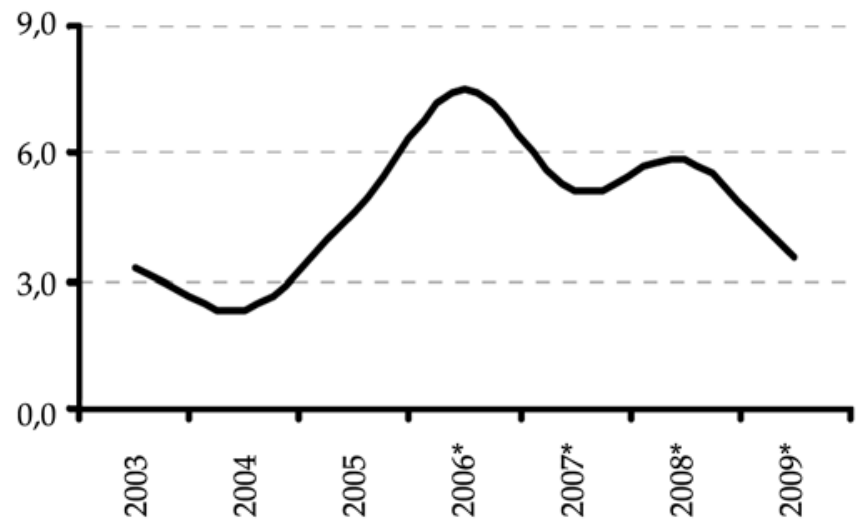

Fuente: Área de Coyuntura - Instituto de Economía - Freya - UdelaR.

En cuarto lugar, no existe, al menos hasta la fecha, evidencia empírica que permita correlacionar la evolución de la votación del FA con datos sociodemográficos. Durante muchos años se consideró razonable esperar que el FA perdiera apoyo en los sectores medios y ganara en el nivel socioeconómico bajo como consecuencia del efecto combinado de los costos de algunas reformas (como el IRPF) y de los beneficios de otras (como la Reforma de la Salud o el Plan Ceibal). Aunque algunos trabajos sugieren que el Programa de Transferencias Monetarias Condicionadas implementado por el FA(PANES) generó un beneficio electoral para el partido de gobierno (Manacorda, Miguel y Vigorito, 2009), el 
Gráfico 14: Costo de gobernar.

Saldos electorales del partido de gobierno en Uruguay (1942-2004)

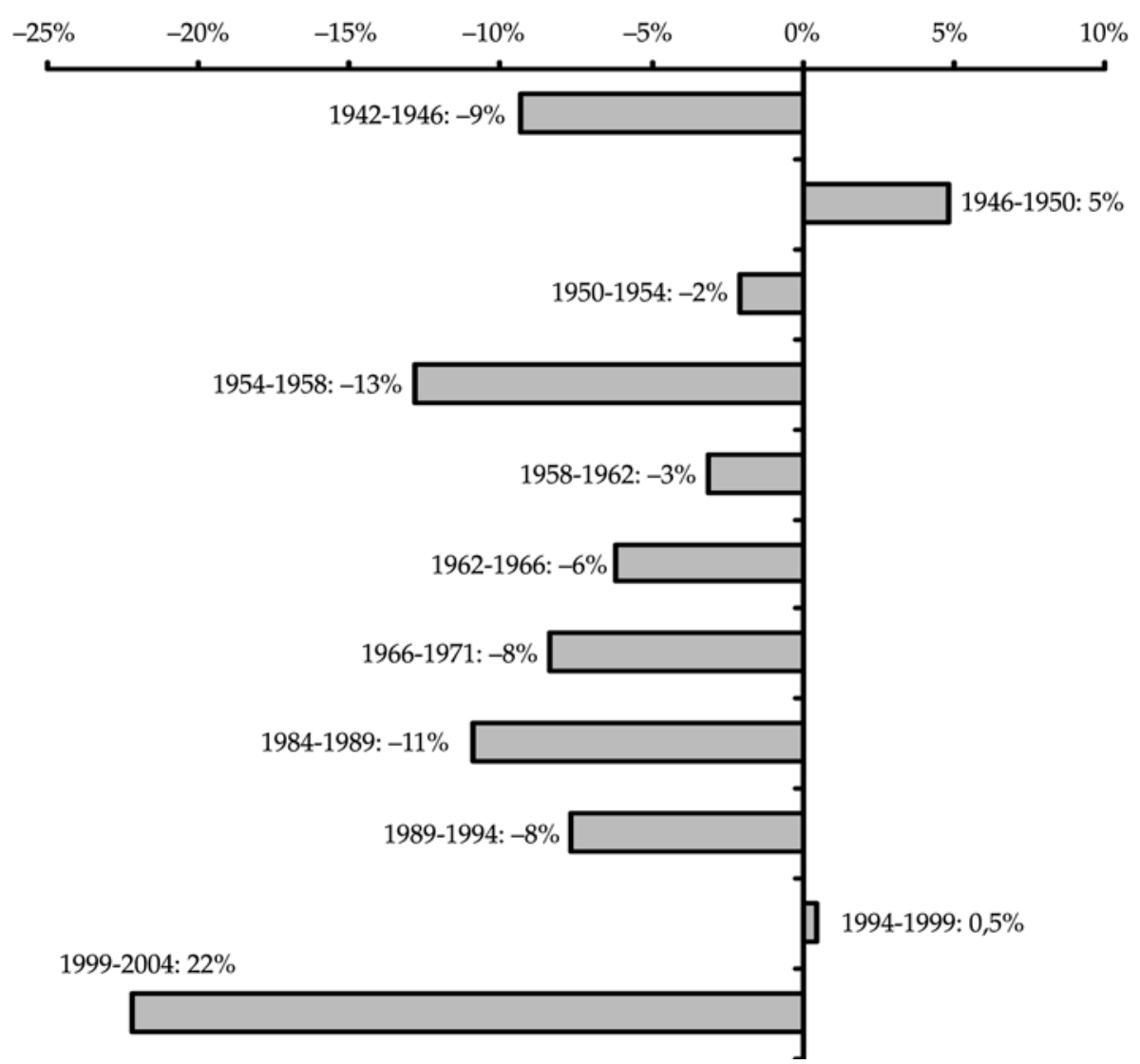

Fuente: Elaboración propia con datos del Banco de Datos PRI-FCS.

comportamiento electoral de los sectores de menores ingresos no experimentó un cambio visible a favor del FA (ver Tabla 12). Como puede verse, tampoco puede visualizarse una correlación obvia entre la variación del desempleo y el comportamiento electoral (Gráfico 15). Maldonado fue el departamento en el que más disminuyó la desocupación durante el quinquenio. Sin embargo, es en ese departamento que se registró la mayor caída del FA. En Río Negro la desocupación aumentó. Sin embargo, durante ese lapso, el FA creció. En Florida, la desocupación bajó casi 10\% pero el FA disminuyó casi 3\%. En Canelones la desocupación disminuyó 8\%. No obstante, el FA perdió casi 2\%. La misma conclusión surge cuando se analiza la evolución de la pobreza y del voto al FA por departamentos (Gráfico 16). 
Tabla 12: Promedio de intención de voto al FA 2004-2009 por nivel socioeconómico

\begin{tabular}{lcr}
\hline Nivel socioeconómico & $\begin{array}{r}2004 \\
(\%)\end{array}$ & $\begin{array}{r}2009 \\
(\%)\end{array}$ \\
\hline Alto y medio alto & 52 & 49 \\
Medio & 50 & 48 \\
Medio bajo & 44 & 45 \\
Bajo & 43 & 41 \\
Total & 47 & 46 \\
\hline
\end{tabular}

Fuente: Equipos - Mori.

\subsection{El fracaso de los dos plebiscitos de reforma constitucional}

Con la elección de octubre ser realizaron dos plebiscitos de reforma constitucional. Los dos fueron promovidos por organizaciones vinculadas a la izquierda. El primero de ellos buscaba encontrar una solución a la cuestión de cómo remover del ordenamiento jurídico la Ley de Caducidad de la Pretensión Punitiva del Estado. El FA resistió desde el principio esta norma y tuvo un papel protagónico en el referéndum que intentó, sin éxito, derogarla en abril de 1989. La presión de la Corte Interamericana de Derechos Humanos de la OEA (que, desde 1992, considera que esta norma contradice principios básicos del derecho humanitario) y de las organizaciones de DDHH en Uruguay obligó al FA, que parecía conforme con la solución adoptada por Vázquez (investigar y procurar hacer justicia en el marco de la ley vigente) a buscar un camino que hiciera posible la remoción de la Ley de Caducidad. Los promotores del proyecto de reforma constitucional descartaron la posibilidad de buscar la derogación de la ley en el Parlamento, porque este mecanismo impediría reabrir los casos ya juzgados. ${ }^{25}$

La segunda reforma procuró introducir el voto epistolar para los ciudadanos uruguayos residentes en el exterior. ${ }^{26}$ Este plebiscito fue promovido por el FA, en el marco de su política de "vinculación con la diáspora". Los partidos de oposición no apoyaron la iniciativa invocando razones de principios. Más allá de las razones de carácter doctrinario invocadas de uno y otro lado, existe cierto consenso en el sistema político uruguayo en cuanto a que una reforma

Texto de la propuesta de anulación de la Ley de Caducidad: “Voto por SI el proyecto de Reforma Constitucional por el que se anulan y declaran inexistentes los artículos $1^{\circ}, 2^{\circ}, 3^{\circ}$ y $4^{\circ}$ de la Ley $N^{\circ} 15.848$, de 22 de diciembre de 1986 (Caducidad del ejercicio de la pretensión punitiva del Estado); se tienen por no pronunciadas las Resoluciones del Poder Ejecutivo que hayan incluido casos en la caducidad establecida por el artículo $1^{\circ}$ de la referida Ley; se dispone que el Poder Judicial continuará de oficio la tramitación de las causas alcanzadas por las disposiciones anuladas como si éstas nunca hubieran existido, no pudiendo invocarse la cosa juzgada en dichas causas hasta el dictado de una nueva sentencia, así como que, respecto de aquellos delitos que fueren prescriptibles y que hayan sido o pudieran haber sido comprendidos en la caducidad dispuesta por el artículo $1^{\circ}$ de la Ley $\mathrm{N}^{\circ} 15.848$, de 22 de diciembre de 1986, no podrá computarse a efectos de la prescripción el período transcurrido entre el 22 de diciembre de 1986 y la fecha de entrada en vigencia de la reforma que se plebiscita".

26 Texto de la propuesta de voto epistolar: "Voto por SI el proyecto de Reforma Constitucional que permite el voto epistolar (por correspondencia) desde el exterior de la República y faculta a la Corte Electoral para instrumentar otros procedimientos". 
Gráfico 15: Variación del desempleo y de la votación del FA entre 2004 y 2009

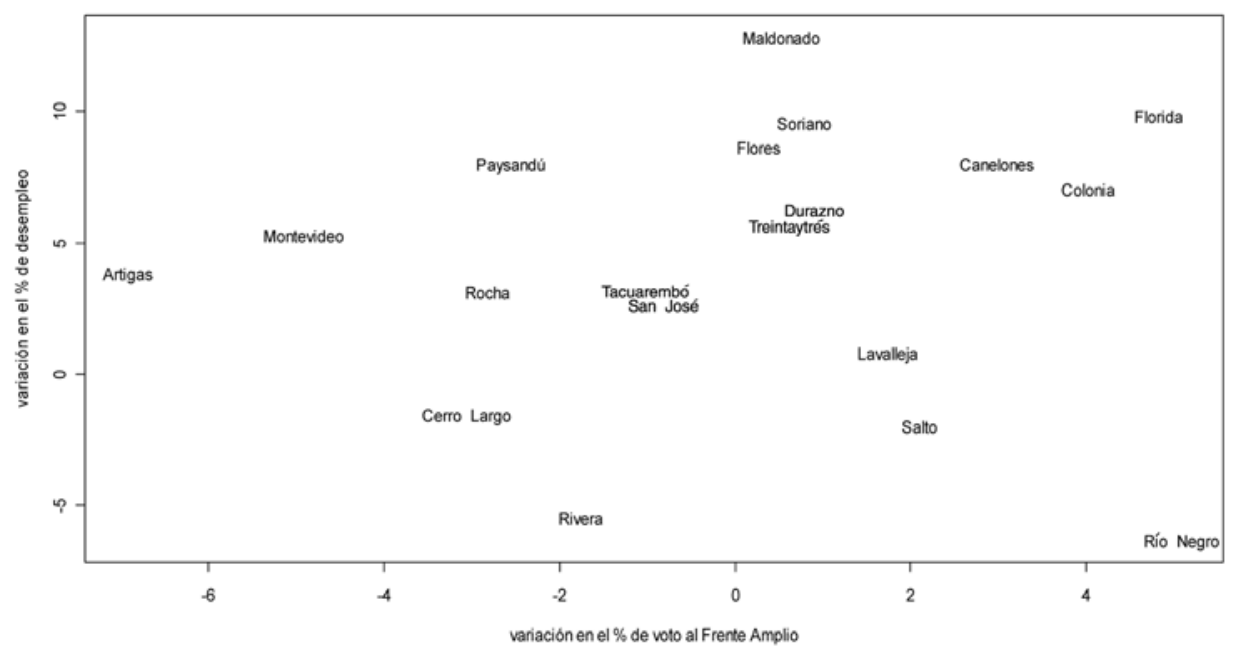

Fuente: Elaborado por Rafael Piñeiro (ICP) con datos del Banco de Datos PRI-FCS.

Gráfico 16: Disminución de la pobreza y variación de la votación del FA entre 2004 y 2009

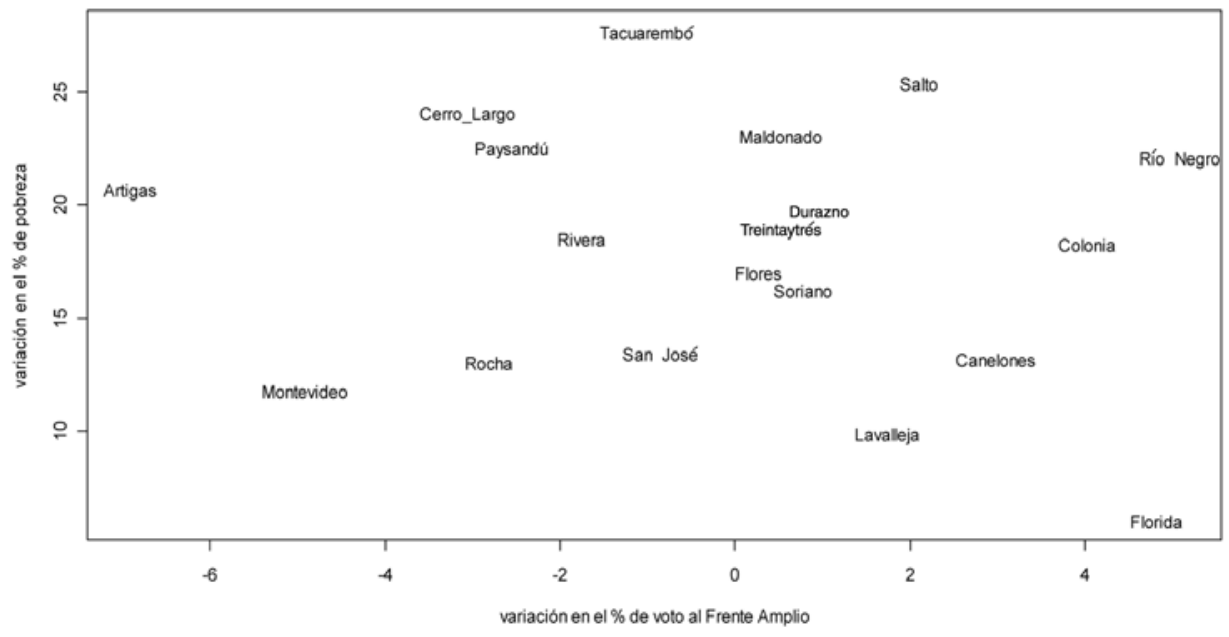

Fuente: Elaborado por Rafael Piñeiro (ICP) con datos del Banco de Datos PRI-FCS. 
que le permita al numeroso colectivo de uruguayos que viven en el extranjero votar en las elecciones nacionales beneficiaría al FA y perjudicaría a los partidos tradicionales.

A pesar de su obvia trascendencia, ninguna de las dos propuestas de reforma constitucional ocupó un lugar importante en el debate público durante el año 2009. Tratándose de asuntos polémicos, en un contexto de relativamente baja información, no debe extrañar que ninguno de los dos haya alcanzando la mayoría requerida para su aprobación (mayoría absoluta de votos emitidos).

Tabla 13: Plebiscitos de reforma constitucional

\begin{tabular}{cc}
\hline Anulación de la Ley de Caducidad & Incorporación de voto epistolar \\
\hline $47,98 \%$ & $37,42 \%$ \\
\hline
\end{tabular}

\section{LOS PRIMEROS PASOS DEL GOBIERNO ELECTO}

"Antes quería cambiar el mundo. Ahora me conformo con arreglar la vereda de mi casa".

José Mujica

A comienzos de los 80, en el contexto de la transición desde el autoritarismo a la democracia y del proceso de institucionalización de la Ciencia Política, Gerardo Caetano, José Rilla y Romeo Pérez Antón propusieron que, para comprender la política uruguaya, había que partir de la base de la "centralidad de los partidos". Los primeros pasos de la gestión del Presidente José Mujica, como se verá a continuación, confirman la "hipótesis partidocéntrica": en Uruguay no gobiernan las personas, gobiernan los partidos. Este punto de partida es fundamental para entender la actual coyuntura. La presidencia de José Mujica es la segunda experiencia de gobierno nacional del Frente Amplio. Existe, por tanto, una amplia zona de contacto entre el gobierno saliente y el entrante. De todos modos, dado que el Presidente tiene, tanto desde el punto de vista institucional como simbólico, un peso innegable, puede advertirse en la marcha del nuevo gobierno la impronta de las convicciones y del estilo del nuevo Presidente.

\section{Continuidad}

El gobierno de Mujica es, antes que nada, el segundo gobierno del Frente Amplio. Esto implica que, en líneas generales, se va a mantener la orientación del gobierno de Vázquez. El segundo gobierno del FA, como el primero, intentará maximizar al mismo tiempo crecimiento económico y distribución del ingreso. La estrategia de desarrollo económico, en lo esencial, será la misma. Fernando Lorenzo, el nuevo ministro, fue uno de los más cercanos colaboradores de Danilo Astori (que ocupó esta cartera durante la presidencia de Vázquez). También persistirá el énfasis en lucha contra la pobreza y la exclusión social que caracterizó a la primera administración frenteamplista. 
Los términos de la ecuación de gobernabilidad serán también similares. El de Mujica también será un gobierno de partido. En la elección de octubre de 2009, el FA logró mantener la mayoría absoluta en las dos cámaras. Al igual que su predecesor, el nuevo Presidente no estará obligado a tejer acuerdos con los partidos de oposición para tramitar la legislación. La gobernabilidad volverá a depender, por ende, de la disciplina de los legisladores frenteamplistas. Como Vázquez, Mujica está obligado a pactar con las distintas fracciones que componen este partido. Al igual que Vázquez, buscando lubricar los acuerdos internos, Mujica designó un gabinete en el que los grupos más importantes son del FA.

Tabla 14: Senadores electos por el FA (2010-2014) y ministros del gabinete de Mujica por fracción

\begin{tabular}{lcc}
\hline \multicolumn{1}{c}{ Fracción } & Senadores & Ministros \\
\hline Espacio 609 & 6 & 4 \\
Frente Líber Seregni & 5 & 3 \\
Partido Socialista & 2 & 2 \\
Partido Comunista & 1 & 1 \\
CAP-L & 1 & 1 \\
Vertiente Artiguista & 1 & 1 \\
Independientes FA & & 1 \\
Total & 16 & 13 \\
\hline
\end{tabular}

Tabla 15: Gabinete Presidente José Mujica (2010)

\begin{tabular}{|c|c|c|c|c|}
\hline Ministerio & Nombre & Sector & Edad & $\begin{array}{l}\text { Formación } \\
\text { académica }\end{array}$ \\
\hline Defensa Nacional & $\begin{array}{l}\text { Luis } \\
\text { Rosadilla }\end{array}$ & $\begin{array}{l}\text { Corriente de Acción y } \\
\text { Pensamiento - Libertad }\end{array}$ & 56 & \\
\hline Desarrollo Social & $\begin{array}{l}\text { Ana María } \\
\text { Vignoli }\end{array}$ & $\begin{array}{l}\text { Partido } \\
\text { Comunista }\end{array}$ & 64 & $\begin{array}{l}\text { Asistente } \\
\text { Social }\end{array}$ \\
\hline Economía y Finanzas & $\begin{array}{l}\text { Fernando } \\
\text { Lorenzo }\end{array}$ & $\begin{array}{l}\text { Nuevo } \\
\text { Espacio }\end{array}$ & 50 & Economista \\
\hline $\begin{array}{l}\text { Educación y } \\
\text { Cultura }\end{array}$ & $\begin{array}{l}\text { Ricardo } \\
\text { Ehrlich }\end{array}$ & $\begin{array}{l}\text { Movimiento de } \\
\text { Participación Popular }\end{array}$ & 61 & $\begin{array}{l}\text { Biólogo y } \\
\text { Bioquímico }\end{array}$ \\
\hline $\begin{array}{l}\text { Ganadería, } \\
\text { Agricultura y Pesca }\end{array}$ & $\begin{array}{l}\text { Tabaré } \\
\text { Aguerre }\end{array}$ & Independiente & 53 & $\begin{array}{l}\text { Ingeniero } \\
\text { Agrónomo }\end{array}$ \\
\hline $\begin{array}{l}\text { Industria, Energía y } \\
\text { Minería }\end{array}$ & $\begin{array}{l}\text { Roberto } \\
\text { Kreimerman }\end{array}$ & Partido Socialista & 51 & $\begin{array}{l}\text { Ingeniero } \\
\text { Químico }\end{array}$ \\
\hline Interior & $\begin{array}{l}\text { Eduardo } \\
\text { Bonomi }\end{array}$ & $\begin{array}{l}\text { Movimiento de } \\
\text { Participación Popular }\end{array}$ & 61 & \\
\hline
\end{tabular}




\begin{tabular}{|c|c|c|c|c|}
\hline Ministerio & Nombre & Sector & Edad & $\begin{array}{l}\text { Formación } \\
\text { académica }\end{array}$ \\
\hline $\begin{array}{l}\text { Relaciones } \\
\text { Exteriores }\end{array}$ & $\begin{array}{l}\text { Luis } \\
\text { Almagro }\end{array}$ & $\begin{array}{l}\text { Movimiento de } \\
\text { Participación Popular }\end{array}$ & 46 & $\begin{array}{l}\text { Abogado } \\
\text { Diplomático }\end{array}$ \\
\hline Salud Pública & $\begin{array}{l}\text { Daniel } \\
\text { Olesker }\end{array}$ & $\begin{array}{l}\text { Partido } \\
\text { Socialista }\end{array}$ & 58 & Economista \\
\hline $\begin{array}{l}\text { Trabajo y } \\
\text { Seguridad Social }\end{array}$ & $\begin{array}{l}\text { Eduardo } \\
\text { Brenta }\end{array}$ & $\begin{array}{l}\text { Vertiente } \\
\text { Artiguista }\end{array}$ & 51 & \\
\hline $\begin{array}{l}\text { Transporte y } \\
\text { Obras Públicas }\end{array}$ & $\begin{array}{l}\text { Enrique } \\
\text { Pintado }\end{array}$ & $\begin{array}{l}\text { Asamblea } \\
\text { Uruguay }\end{array}$ & 52 & \\
\hline $\begin{array}{l}\text { Turismo y } \\
\text { Deporte }\end{array}$ & $\begin{array}{l}\text { Héctor } \\
\text { Lescano }\end{array}$ & $\begin{array}{l}\text { Alianza } \\
\text { Progresista }\end{array}$ & 60 & Veterinario \\
\hline $\begin{array}{l}\text { Vivienda, Ordenamiento } \\
\text { Territorial y Medio } \\
\text { Ambiente }\end{array}$ & $\begin{array}{l}\text { Graciela } \\
\text { Muslera }\end{array}$ & $\begin{array}{l}\text { Movimiento de } \\
\text { Participación Popular }\end{array}$ & 46 & Arquitecta \\
\hline $\begin{array}{l}\text { Oficina de Planeamiento } \\
\text { y Presuesto }\end{array}$ & $\begin{array}{l}\text { Gabriel } \\
\text { Frugoni }\end{array}$ & $\begin{array}{l}\text { Movimiento de } \\
\text { Participación Popular }\end{array}$ & 44 & Economista \\
\hline
\end{tabular}

Fuente: Elaboración propia a partir de información publicada en prensa.

\section{Cambios}

El Presidente en Uruguay, en términos comparados, es institucionalmente fuerte. También, como es la norma en los sistemas presidenciales, su figura es muy importante desde el punto de vista simbólico. Sin embargo, existen importantes contrapesos a la concentración de poder en el Presidente. Generalmente el Presidente no es el líder del partido sino el jefe de una de sus fracciones. Esto es exactamente lo que ocurre con Mujica: es el líder del MPP, pero no es el líder del FA. Vázquez, en cambio, llegó a la presidencia diez años después de haberse convertido en el líder de todo el FA. Mujica, por ende, está mucho más obligado que Vázquez a pactar con las distintas fracciones que componen la interna frenteamplista. En materia de equidad de género, el nuevo gabinete representa un retroceso respecto al de Tabaré Vázquez: “El nuevo Ejecutivo cuenta con sólo dos mujeres ministras (Graciela Muslera en el Ministerio de Vivienda Ordenamiento Territorial y Medio Ambiente y Ana Vignoli en el MIDES) y dos subsecretarias (María Simón en Educación y Cultura y Lilian Kechichián en Turismo y Deporte). Con esto Uruguay pasa de una tasa de mujeres ministras del $23,1 \%$ en el primer gabinete de Vázquez a un 15,4\% en la actualidad" (Johnson y Pérez 2010: 155). ${ }^{27}$ parlamentarios en disputa). En las elecciones departamentales de mayo de 2010, dos de las diputadas también fueron electas como Intendentas de sus respectivos departamentos. Al perder estas dos mujeres, la tasa de presencia femenina en el Parlamento bajó al 13,1\%, cifra que coloca a Uruguay en el lugar 15 entre los 19 países de América Latina. Un análisis exhaustivo del reciente ciclo electoral desde la perspectiva de género puede leerse en Johnson y Pérez (2010) 
La agenda del nuevo gobierno es una combinación del programa de gobierno del FA con las obsesiones personales del propio Mujica. ¿Cuáles son las prioridades del presidente electo? En materia de políticas sociales, educación y vivienda. En materia de desarrollo económico, su apuesta principal es a la modernización del agro, emulando la cooperación entre universidades y productores agropecuarios que caracteriza el modelo neozelandés. También desde Nueva Zelanda llega otra de sus prioridades: la reforma del Estado. Como puede verse, aunque Mujica ganó la primaria del FA proclamando la necesidad de un "giro a la izquierda" en las orientaciones de políticas públicas del segundo gobierno frenteamplista, su gobierno tendrá, como el de Vázquez, una orientación general de centroizquierda.

Para terminar de caracterizar el nuevo gobierno hay que hacer referencia también al estilo político del presidente electo. Acá se aprecia un contraste muy fuerte entre los dos gobernantes frenteamplistas. En primer lugar, a diferencia de Vázquez, Mujica se esfuerza por construir un buen clima de diálogo con la oposición. Impulsó con decisión la incorporación de representantes del Partido Nacional, del Partido Colorado y del Partido Independiente en los directorios de las empresas públicas. La idea es que la izquierda asuma la responsabilidad principal en la gestión de estas empresas, pero permitiendo que la oposición, a través de una representación minoritaria, pueda colaborar con la gestión y ejercer el contralor. Esta iniciativa de Mujica implica recobrar la tradición de la "coparticipación", lógica de relacionamiento entre los partidos políticos que caracterizó durante décadas a la democracia uruguaya. La propensión al diálogo con la oposición de Mujica se manifiesta también en la convocatoria a comisiones de trabajo interpartidarias que tienen como cometido llegar a acuerdos sustantivos en cuatro áreas de políticas que el Presidente considera fundamentales: educación, seguridad, energía y cambio climático. El nuevo Presidente, aquel viejo guerrillero, hace gala de una concepción ejemplarmente pluralista de la política. En su discurso de toma de posesión del cargo, el $1^{\circ}$ de marzo, dijo ante la Asamblea General: "Me estoy imaginando el proceso político que viene, como una serie de encuentros, a los que unos llevamos los tornillos y otros llevan las tuercas. Es decir, encuentros a los que todos concurrimos, con la actitud de quien está incompleto sin la otra parte. En ese tono se va a desarrollar el próximo gobierno del Frente Amplio".

En segundo lugar, y como consecuencia natural de lo que acaba de señalarse, Mujica muestra una tendencia muy fuerte a posicionarse ante la opinión pública como "presidente de todos" y no como "presidente frenteamplista". Esta es una tensión clásica, que deben manejar todos los gobernantes. Mujica tendió muy rápidamente a tomar distancia del FA. Se acercó a los partidos de oposición, y se alejó, en algunos temas muy importantes, del partido que lo llevó a la presidencia. Un ejemplo clarísimo de esta tendencia es su iniciativa, finalmente frustrada por la resistencia de la mayoría de los grupos del FA de, por razones humanitarias, favorecer la liberación de presos de más de 70 años condenados por haber cometido violaciones a los derechos humanos durante la dictadura. Durante 25 años, la izquierda uruguaya luchó por juzgarlos y encarcelarlos. Vázquez, interpretando de una forma diferente a los presidentes anteriores la Ley de Caducidad, logró que el 
núcleo principal del elenco de militares y civiles que gobernaron durante el régimen autoritario marchara a prisión. Mujica, en cambio, sorprendiendo a tirios y troyanos, se mostró partidario de liberarlos. Tabaré Vázquez tuvo algunos enfrentamientos con el FA. Los dos más notorios fueron su apoyo a la iniciativa de Danilo Astori de firmar un TLC con EE.UU. (frenada por el FA) y el veto presidencial a los capítulos relacionados con el aborto en la Ley de Salud Sexual Reproductiva (ley promovida por la gran mayoría de la bancada del FA). Sin embargo, en líneas generales mantuvo una buena sintonía con su propio partido.

En tercer lugar, sus niveles de exposición pública son muy superiores a los de Vázquez. El ex presidente graduaba con enorme cuidado sus energías y administraba con todo celo sus intervenciones en el debate público. Fue un presidente mesurado, discreto. Mujica, en cambio, trabaja cada día como si fuera el último y no muestra interés en administrar su participación en el debate público. El estilo de Vázquez fue muy criticado por la oposición, que solía cuestionarle ser un "presidente ausente". Sin embargo, a la larga, esto lo ayudó mucho a evitar el deterioro de su imagen. Vázquez llegó al final de su mandato con niveles inusuales de simpatía. Según CIFRA, Mujica parte de niveles un poco superiores a los de Vázquez en marzo de 2005 (71\% contra $63 \%$ de Vázquez en marzo de 2005). ${ }^{28}$ Mujica logró ser el sucesor de Vázquez. Cabe preguntarse si logrará llegar al final de su mandato con niveles de aprobación similares a los de su predecesor. Teniendo en cuenta su tendencia a la sobreexposición esto no parece tarea sencilla.

La elección de Tabaré Vázquez inició un tiempo nuevo, el del predominio político del FA. A su vez, el ascenso de José Mujica, figura histórica del MLN-Tupamaros, cierra un ciclo de gran trascendencia en la historia política uruguaya. En 1962 la izquierda uruguaya sufrió una derrota electoral muy severa. El viejo Partido Socialista, en particular, perdió su representación en el Parlamento. Fue tan impactante el resultado electoral que el sociólogo Aldo Solari, uno de los precursores de la Ciencia Política uruguaya, escribió un "Réquiem para la izquierda", intentando dar cuenta de las razones del fracaso. El naufragio de 1962 profundizó la tendencia al escepticismo sobre la posibilidad de desplazar a los partidos tradicionales del poder por la vía electoral que venía gestando en la sociedad uruguaya. La revolución cubana, por su parte, parecía mostrar que era posible catalizar los procesos de cambio a través de otras formas de lucha. El MLN-T se forjó en ese clima de profundo desencanto ante la lucha electoral. Casi medio siglo después, uno de los fundadores de aquel movimiento guerrillero, recorriendo el camino de las urnas que antes desechaba, terminó convirtiéndose en presidente. Suele decirse que Uruguay tiene instituciones democráticas potentes. Me cuesta imaginar una demostración más elocuente. 


\section{REFERENCIAS}

Altman, David, 2010. "The 2009 elections in Uruguay", Electoral Studies (2010), doi:10.1016/j. electstud.2010.04.014, en prensa.

Altman, David, Antonio Cardarello yAdolfo Garcé. 1999. "El Costo de Gobernar". Posdata (270), pp. 93-96.

Buquet, Daniel. 2009. “Uruguay 2008: de las reformas a la competencia electoral”, Revista de Ciencia Política, Volumen 29, No 2, 2009, 611-632.

Bango, Julio. 2009. “Hacia una estrategia de desarrollo con justicia social. La contribución de las políticas sociales presentes y futuras: el por qué y el cómo", Elissalde, Roberto (comp.). Gozos y sombras del gobierno progresista, Montevideo: Dedos, 267-292.

Cardarello, Antonio. 2009. "El Frente Amplio. Creación, evolución y perspectivas de futuro". Ponencia presentada en el Instituto de Formación del Frente Progresista y Popular con el apoyo de la Fundación Políticas Públicas, Buenos Aires.

Chasquetti, Daniel. 2008. "Uruguay 2007: El complejo año de las reformas", Revista de Ciencia Política, Volumen 28, No 1, 2008, 385-403.

Chasquetti, Daniel. 2010. “El financiamiento de la política en Uruguay 2009”, Documento elaborado para IDEA Internacional y la Organización de Estados Americanos. Inédito de próxima publicación.

Colomer, Joseph. 2002. "Las elecciones primarias presidenciales en América Latina y sus consecuencias políticas", en Cavarozzi, Marcelo y Juan Manuel Abal Medina (h.) (compiladores). 2002. El asedio a la política. Los partidos latinoamericanos en la era neoliberal. Homo Sapiens Ediciones y Konrad Adenauer Stiftung, Rosario,

De Armas, Gustavo. 2009. “Debilitamiento del efecto demográfico y consolidación de un nuevo sistema partidario: Evidencia de las elecciones 2009 en Uruguay", Revista Uruguaya de Ciencia Política, Volumen 18-01, enero-diciembre 2009.

Garcé, Adolfo. 2006. Donde hubo fuego. El proceso de adaptación del MLN-Tupamaros a la legalidad y a la competencia electoral (1985-2004), Fin de Siglo, Montevideo.

Garcé, Adolfo. 2009. “Cómo Mujica y Lacalle pasaron de desafiantes a favoritos". Ponencia en Seminario "Monitor Electoral Universidad Católica - Konrad Adenauer Siftung". Disponible en: http:/ /www. kas.de/upload/dokumente/2009/04/RSP_0409_Garce.pdf.

Johnson, Niki y Verónica Pérez. 2010. Representación (s)electiva: Una mirada feminista a las elecciones uruguayas 2009. Cotidiano Mujer - UNIFEM, Montevideo. Disponible en: http:/ /www.cotidianomujer.org.uy/ pub_miradafeminista.pdf .

Rodríguez, Juan Manuel, Beatriz Cozzano y Graciela Mazzuchi. 2007. Relaciones Laborales y Modelo de Desarrollo. Universidad Católica: Montevideo.

Zuasnábar. 2009. “Evaluación de las Elecciones Internas. Análisis y perspectivas de las Elecciones Nacionales de Octubre". Monitor electoral Universidad Católica - Konrad Adenauer Siftung, $2^{a}$ sesión.

Manacorda, Marco, Edward Miguel and Andrea Vigorito. 2009. "Government Transfers and Political Support", Working Paper 14702, National Bureau of Economic Research, http://www.nber.org/ papers/w14702.

Adolfo Garcé es Candidato a Doctor en Ciencia Política. Es Profesor Adjunto en Régimen de Dedicación Total en el Instituto de Ciencia Política de la Facultad de Ciencias Sociales, Universidad de la República, Montevideo. Integra el Sistema Nacional de Investigadores (Nivel 1). 
